ORNL/TM-2014/549

Indoor Climate and Moisture Durability Performances of Houses with Unvented Attic Roof Constructions in a MixedHumid Climate

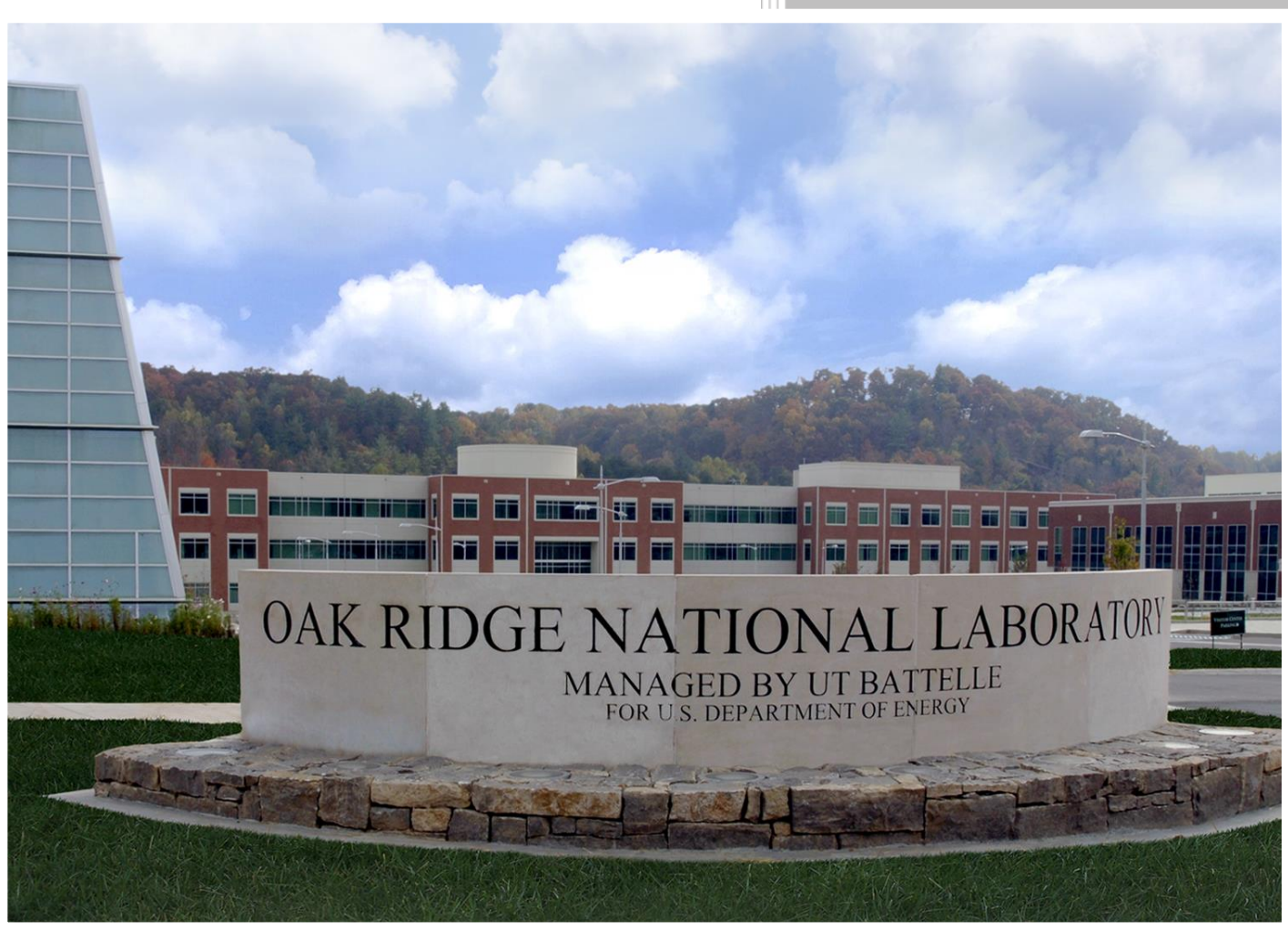

Approved for public release; distribution is unlimited.
Simon B. Pallin Phillip R. Boudreaux Roderick K. Jackson October 2014 


\section{DOCUMENT AVAILABILITY}

Reports produced after January 1, 1996, are generally available free via US Department of Energy (DOE) SciTech Connect.

Website http://www.osti.gov/scitech/

Reports produced before January 1, 1996, may be purchased by members of the public from the following source:

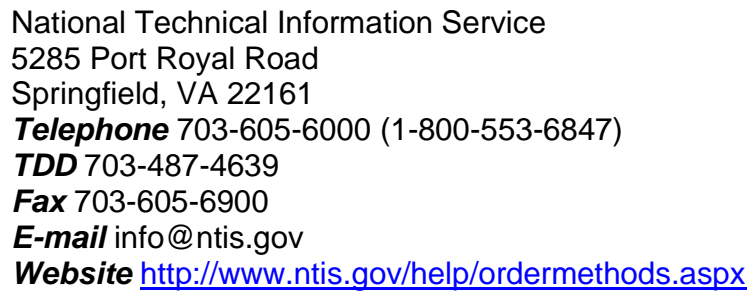

Reports are available to DOE employees, DOE contractors, Energy Technology Data Exchange representatives, and International Nuclear Information System representatives from the following source:

Office of Scientific and Technical Information

PO Box 62

Oak Ridge, TN 37831

Telephone 865-576-8401

Fax 865-576-5728

E-mail reports@osti.gov

Website http://www.osti.gov/contact.html

This report was prepared as an account of work sponsored by an agency of the United States Government. Neither the United States Government nor any agency thereof, nor any of their employees, makes any warranty, express or implied, or assumes any legal liability or responsibility for the accuracy, completeness, or usefulness of any information, apparatus, product, or process disclosed, or represents that its use would not infringe privately owned rights. Reference herein to any specific commercial product, process, or service by trade name, trademark, manufacturer, or otherwise, does not necessarily constitute or imply its endorsement, recommendation, or favoring by the United States Government or any agency thereof. The views and opinions of authors expressed herein do not necessarily state or reflect those of the United States Government or any agency thereof. 
Energy and Transportation Science Division

\title{
INDOOR CLIMATE AND MOISTURE DURABILITY PERFORMANCES OF HOUSES WITH UNVENTED ATTIC ROOF CONSTRUCTIONS IN A MIXED-HUMID CLIMATE
}

\author{
Simon B. Pallin \\ Phillip R. Boudreaux \\ Roderick K. Jackson
}

Date Published: October 2014

Prepared by

OAK RIDGE NATIONAL LABORATORY

Oak Ridge, Tennessee 37831-6283

managed by

UT-BATTELLE, LLC

for the

US DEPARTMENT OF ENERGY

under contract DE-AC05-00OR22725 



\section{CONTENTS}

Page

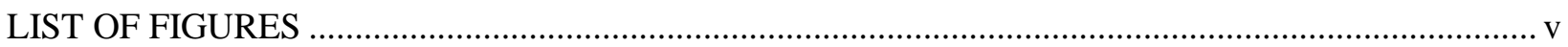

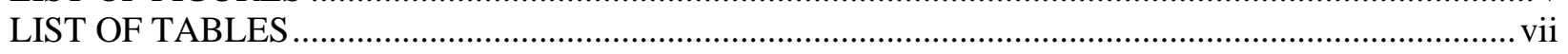

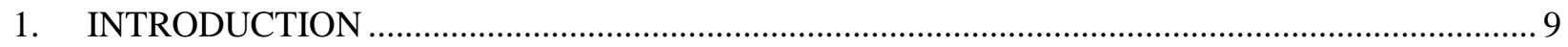

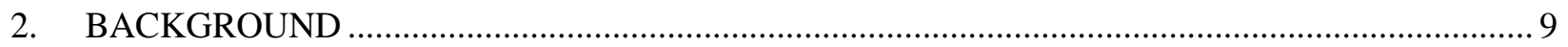

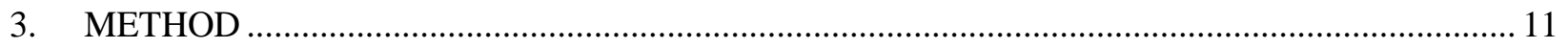

3.1 A RESEARCH HOUSE WITH OCCUPANCY SIMULATION .................................... 12

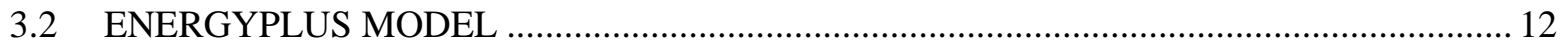

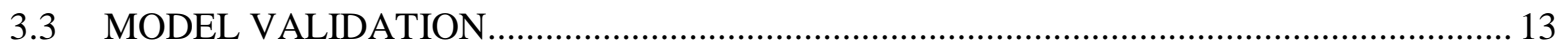

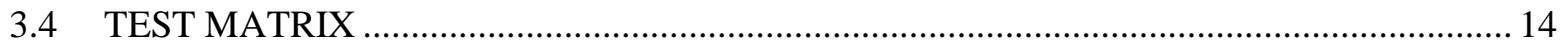

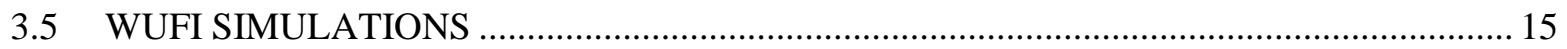

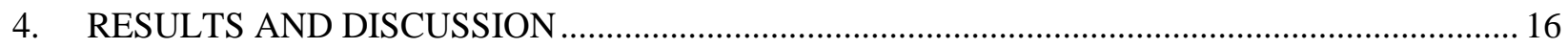

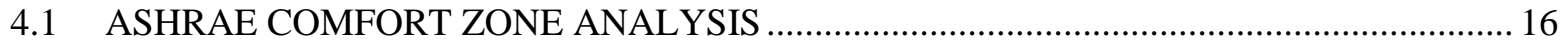

4.2 MOISTURE DURABILITY ASSESSMENT OF ROOF ASSEMBLY …............................. 24

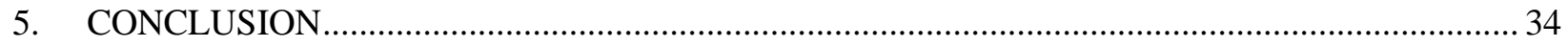

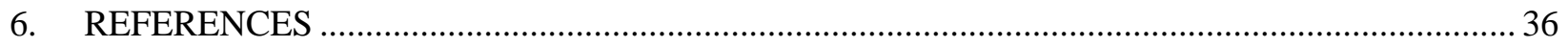





\section{LIST OF FIGURES}

Figures

Fig. 1. An unvented attic is a very complex hygrothermal system. .................................................. 10

Fig. 2. Flow of project from creating the EnergyPlus model to the parametric set of modeling outputs.

Fig. 3. Flow of project from the output of the parametric set of modeling outputs to the final determination of the most appropriate set of key input parameters for keeping the house comfortable and the roof assembly durable.....

Fig. 4. The validated model output of zonal temperature and absolute humidity compared with measured data.

Fig. 5. The drawing at left illustrates the simulation model created in WUFI1D, representing the unvented attic roof assembly with its different materials and thicknesses.....

Fig, 6. ASHRAE Standard 55 defined comfort zone, including the simulated hourly indoor conditions for the 411 simulation scenarios.

Fig. 7. The outliers of four simulation scenarios are presented.

Fig. 8. A sensitivity analysis of the parameter influence on the outliers shows that air leakage between the attic and the outdoor environment has the highest impact on the number of hours with an indoor climate outside the defined comfort zone.

Fig. 9. The upper outliers of three simulation scenarios are presented.

Fig. 10. A comparison between the worst-case scenario (red), which has a high indoor moisture generation rate, with a scenario with low indoor moisture generation.

Fig. 11. A sensitivity analysis of the parameter influence on the upper outliers shows that air leakage through the building enclosure has the second largest impact on indoor humidity levels.

Fig. 12. The air leakage path through the components of the building enclosure can be defined as a direct or an indirect air leakage path.

Fig. 13. The relative humidity of the surface material of an air leakage path is affected by the hygrothermal conditions of the inflowing air.

Fig. 14. The phenomenon of a critical moisture peak when air leaks through a component of the building enclosure is illustrated in a psychrometric chart.

Fig. 15. An overview of the described critical moisture peak depicts the phenomenon illustrated in Figures 12-14.

Fig. 16. The variation in average moisture content of the wooden sheathing is presented for three different simulation scenarios with a low, mediate, and high air leakage rate between the attic and the exterior environment.

Fig. 17. The variation in average moisture content of the wooden sheathing is presented for three different simulation scenarios with a low, mediate, and high air leakage rate between the indoor and the outdoor environments.

Fig. 18. A sensitivity analysis of the influence of five varying input parameters on the moisture content of the wood sheathing shows that indoor moisture generation rate and the air leakage rate through the roof assembly (air leakage path) have the highest impact. 



\section{LIST OF TABLES}

\section{Tables}

Table 1. Modeling uncertainty of the validated EnergyPlus model ...................................................... 14

Table 2. Matrix values for simulation group................................................................................... 15

Table 3. The number of hours for each simulated case when indoor climate conditions are outside

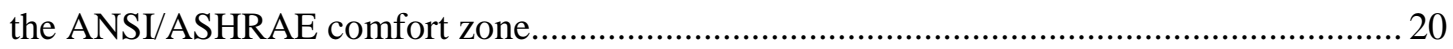

Table 4. The number of hours for each simulated case where the indoor climate conditions are outside the upper limits of the defined ANSI/ASHRAE comfort zone.

Table 5. The maximum moisture content of the wooden roof sheathing does not reach critical level when simulated with a low indoor moisture generation rate

Table 6. Maximum moisture content levels reach risky levels when the air leakage between the indoor and outdoor environment is low and when air leakage rates through the roof assembly are simulated as mediate.

Table 7. Maximum moisture contents of the simulated cases with an assumed high rate of indoor moisture generation.

Table 8. The variation in moisture content of the wooden sheathing is presented for six different simulation scenarios in Figs. 16 and 17 



\section{INTRODUCTION}

A sealed or unvented attic is an energy-efficient envelope component that can reduce the amount of energy a house consumes for space conditioning if the air handler and/or ducts are located in the attic. The attic is typically sealed by using spray foam on the underside of the roof deck and covering the soffit, ridge and gable vents to minimize air leakage from the attic to the outside. This approach can save up to $10 \%$ in space-conditioning energy when ducts are located in the attic (DOE 2013).

Past research done by ORNL and Florida Solar Energy Center suggests that in more hot, humid climates, an unvented attic could potentially create a more humid, uncomfortable living environment than a vented attic (Colon 2011, Boudreaux, Pallin et al. 2013). Research showed that controlling the higher indoor humidity could reduce the energy savings from the sealed, unvented attic, which in turn would decrease the energy savings payback. Research also showed that the roof assembly (5.5 inches of open-cell foam, linch of closed-cell foam, OSB, felt paper, and asphalt shingles) stored moisture, thus acting as a moisture buffer. During the fall and winter, the roof assembly stored moisture and during the spring and summer it released moisture. This phenomenon is not seen in a vented attic, in which the air exchange rate to the outside is greater and, in the winter, helps to dehumidify the attic air. It was also seen that in a vented attic, the direction of water vapor diffusion is on average from the attic to the interior of the house. Air leakage from the attic to the interior also occurs during more of the year in a house with an unvented attic than in one with a vented attic. These discoveries show that the moisture dynamics in a house with an unvented attic are much different from those in a house with a vented attic.

This study reports on a series of computer model investigations completed to determine the key variables impacting indoor comfort and the durability of roof assemblies against moisture. The key variables investigated were the leakage area from the attic to the outside, leakage area from the attic to the interior, leakage area from the interior to the outside, supply duct leakage in the attic, and interior moisture generation. These investigations are described in this report.

\section{BACKGROUND}

Oak Ridge National Laboratory (ORNL) studied the energy efficiency of an unvented attic in a wholehouse retrofit package implemented on one of three research homes in the mixed-humid climate of Knoxville, Tennessee. ORNL found that the research house with an unvented attic had higher humidity in the attic and interior compared with a research house next door with a vented attic and the same floor plan. ORNL investigated eight real houses in total, four with vented attics and four with unvented attics. On average, the houses with unvented attics had higher interior and attic moisture than those with vented attics. For more information on these homes see the final report (Boudreaux, Pallin et al. 2013).

Figure 1 shows the different possible pathways by which moisture can travel throughout the home. Moisture can travel by diffusion and/or by air flow between the attic and the exterior and between the attic and the living space. The moisture is driven both by differences in the absolute moisture content of the air between the two zones, and by air pressure differences between the two zones. A heating, ventilation, and air-conditioning (HVAC) system dehumidifies the air when in cooling mode, and duct leakage can have a significant effect on the ambient conditions in the attic because it causes the HVAC system to run (and thus dehumidify the space) more frequently. While it is running, the HVAC system may also cause a pressure difference between the zones that will drive air flow. Finally, it has been proposed that solar-driven moisture may make its way through the roof assembly and may add moisture to the attic space. 


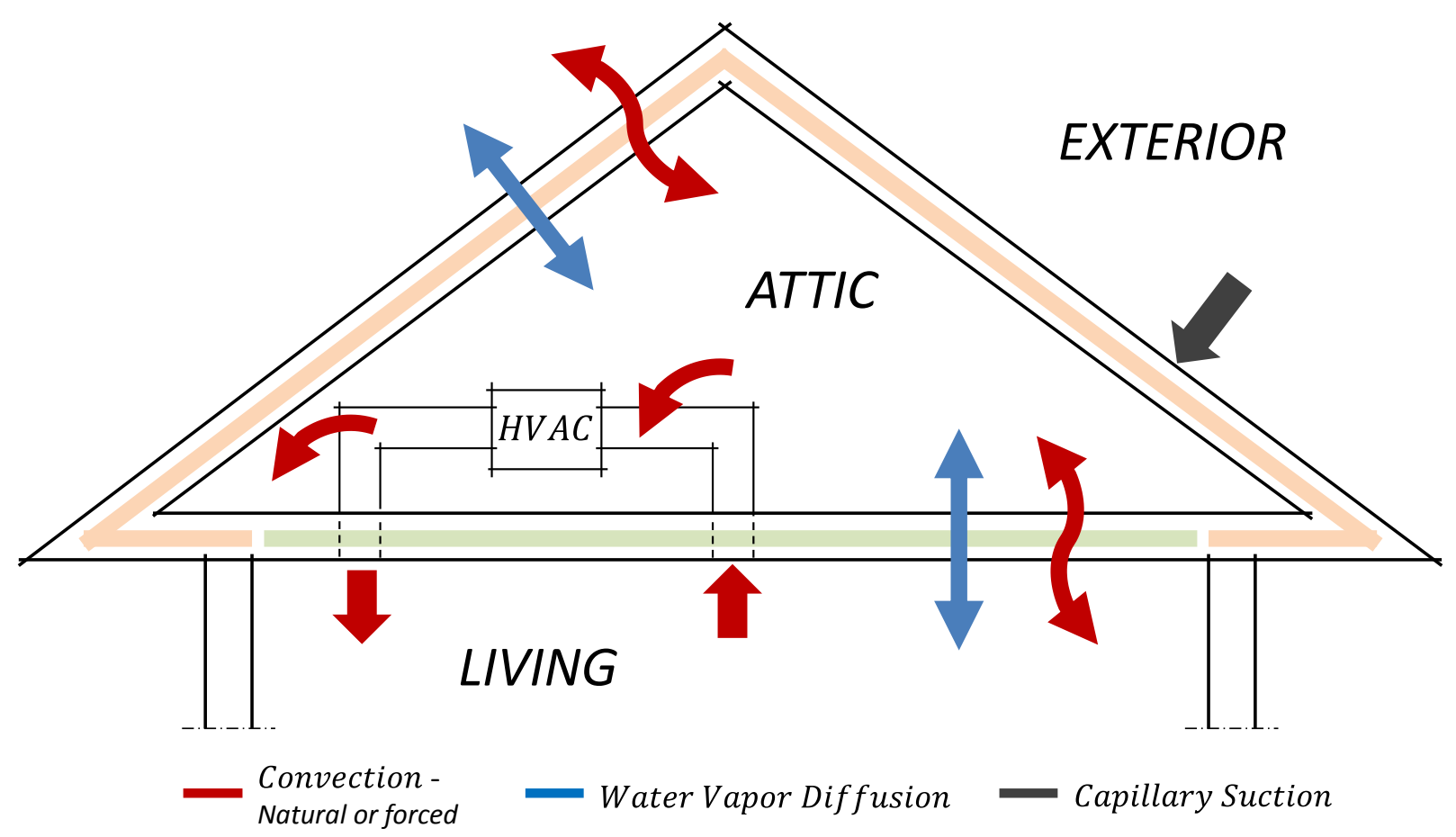

Fig. 1. An unvented attic is a very complex hygrothermal system. The attic environment becomes an intermediate environment that is affected by both the indoor and outdoor climate, and the characteristics of the HVAC system. The arrows depict the direction of the heat, air, and moisture transfer mechanisms that are relevant for the attic environment.

During 2013, ORNL investigated the moisture pathways shown in Fig. 1 using two real houses in the mixed humid climate, a vented attic and an unvented attic house of the same floor plan, orientation, and location (Boudreaux, Pallin et al. 2013). One of the most significant findings was that solar-driven moisture transfer does not occur in any significant amount, and that such a moisture transport mechanism is unlikely. Further, based on the simulations done in that study, if solar-driven moisture were present, although that is very unlikely, it would not increase the moisture content of the roof deck by any significant amount.

After measuring the air leakage between the sealed attic and the outside, we found that it contributed $25 \%$ of the whole-house air leakage, which was more than expected. The leakage rate from the attic to the outside can influence the latent load on the house and will be studied in this report. In addition, the roof deck was found to be a significant moisture storage media. During the fall and winter, the moisture content of the assembly increased, and during the spring and summer, it decreased. Although the moisture from the foam and roof deck was expelled, it probably made its way into the interior of the house, as during this time the air movement was from the attic into the house. Unfortunately, the air pressure difference between the attic and outside was not measured during this experiment, so the extent of air movement between the attic and outside could not be determined.

It is difficult to determine how all the variables described interact to affect the humidity in a home, yet it is crucial that we understand the effect of these variable on the indoor climate and moisture durability of the roof deck so that appropriate mitigation steps can be taken to avoid uncomfortable living spaces and risky roof assemblies. To understand this, we undertook a hybrid approach combining experiments in a real house with advanced modeling to determine how the various leakage areas-between attic and outside, attic and living space, and living space and the outside - as well as the interior latent heat 
generation and attic supply leakage, affect both the interior comfort level and the moisture durability of the roof deck. Exploring all these variables required a full parametric analysis with a model that was validated using a real house.

\section{METHOD}

To understand which variables most affect the comfort in the interior environment and the moisture durability of the roof deck when the attic is unvented, a sensitivity analysis of five important variables was conducted. To accomplish this, an EnergyPlus model of a real research house in the mixed-humid climate was created. This model employed two advanced features in EnergyPlus: the airflow network (AFN) and the effective moisture penetration depth (EMPD) modules. These two modules are critical to the success of this experiment in correctly reflecting the movement of moisture due to air convection and the diffusion of moisture into and out of materials. To the authors' knowledge, these two modules have never before been used to investigate the moisture performance of unvented attics. After the model was complete, it was validated using a whole year of measured interior and attic temperature and absolute humidity data. After the model was validated, five different key input parameters were chosen, each related to the envelope, that were expected to most affect the indoor comfort. Four of these variables had three possible input values, and the other had six. A parametric set of models was run which included all combinations of the variables for a total of 486 models. The results of the models were assessed for indoor comfort and were also used in the WUFI software to assess the moisture durability of the roof deck. After these assessments were completed, we determined which key input variable values were the most important to maintaining comfortable indoor conditions and roof assembly durability for the mixedhumid climate. The following sections briefly describe each of the steps in the process, and Figs. 2 and 3 illustrate the flow of the research in this project.

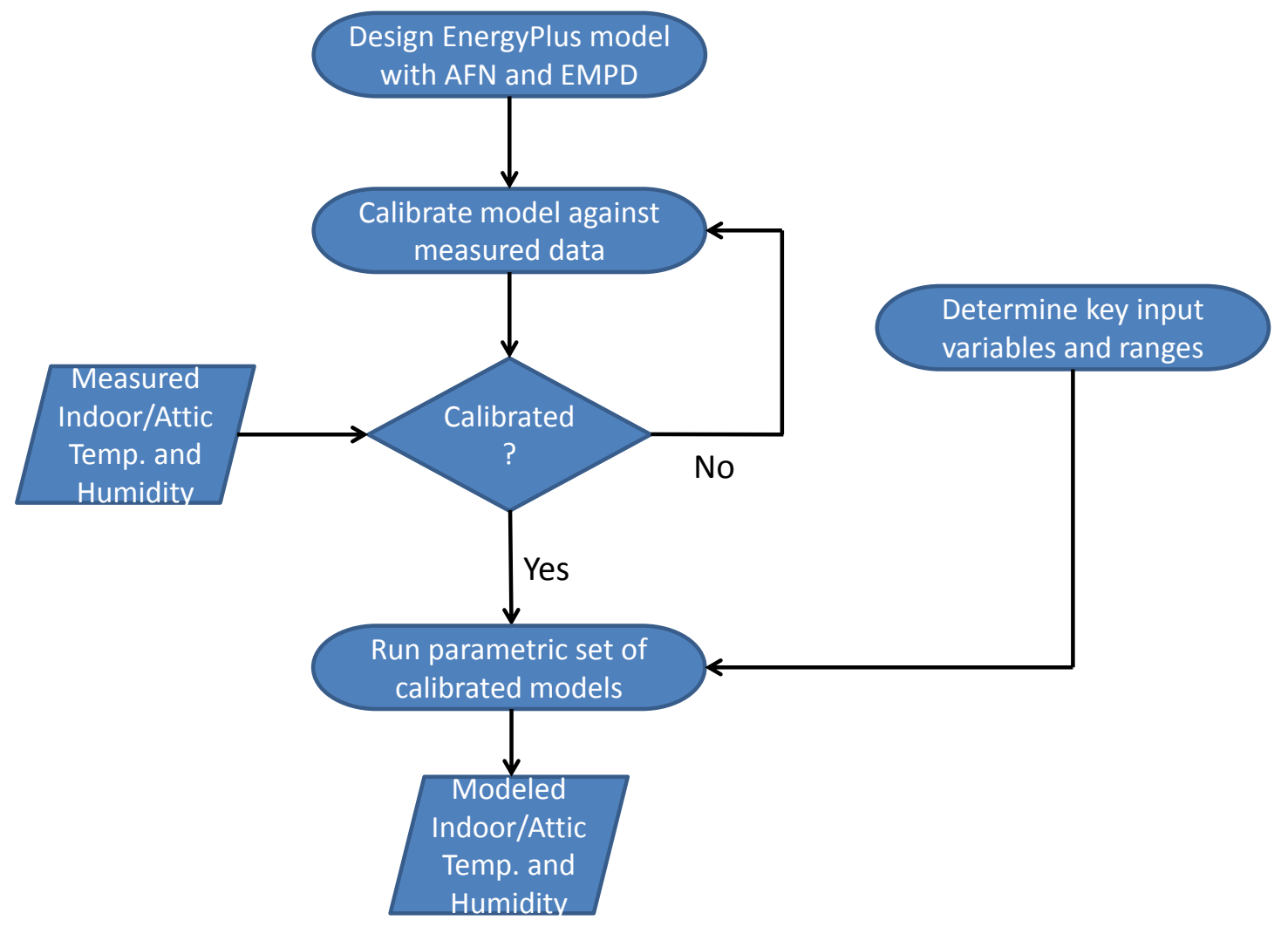

Fig. 2. Flow of project from creating the EnergyPlus model to the parametric set of modeling outputs. 


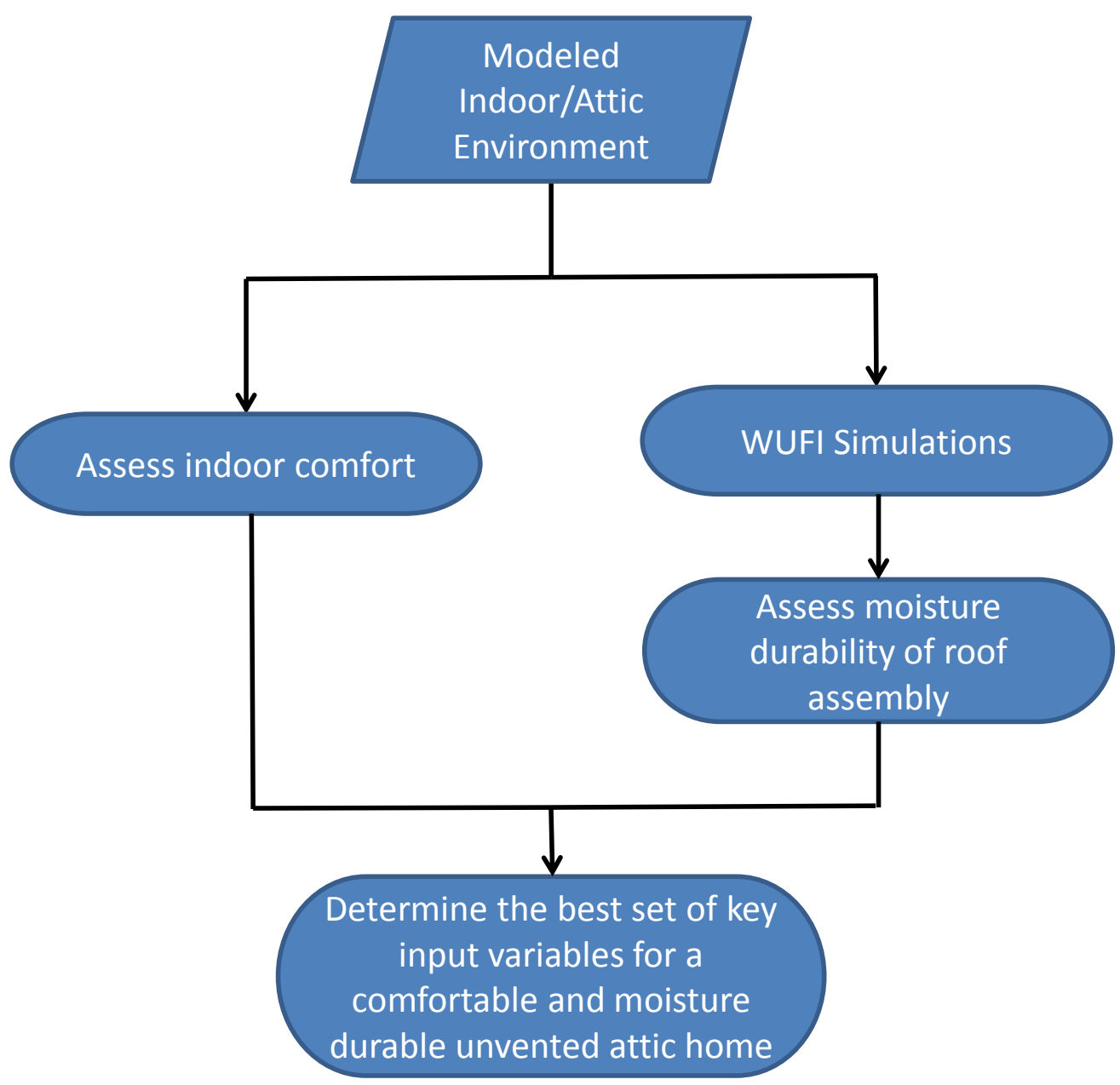

Fig. 3. Flow of project from the output of the parametric set of modeling outputs to the final determination of the most appropriate set of key input parameters for keeping the house comfortable and the roof assembly durable.

\subsection{A RESEARCH HOUSE WITH OCCUPANCY SIMULATION}

In 2009, three research houses were built with differing levels of energy efficiency. The houses are extensively monitored for end-use energy consumption and the thermodynamic and hygrothermal performance of the envelope. The house that was used for this study is a 2,400 $\mathrm{ft}^{2}$ home with an unvented attic, an air change rate of $3.4 \mathrm{ACH} 50$, and simulated occupancy. For more information on the house, see reports by Christian et al. and Boudreaux et. al. (Christian, Gehl et al. 2010, Boudreaux, Gehl et al. 2012).

\subsection{ENERGYPLUS MODEL}

EnergyPlus was used to model the interior and attic temperature and humidity conditions of the unvented research home described above. The AFN and EMPD modules were used. The AFN allows EnergyPlus to simulate heat, air, and moisture movement in a house due to interzonal air flows caused by pressure differences resulting from wind or a forced-air HVAC system. The AFN can also account for duct leakage. (For more information on the AFN, see the work by $\mathrm{Gu}(\mathrm{Gu} 2007)$. To correctly model the infiltration/exfiltration and interzonal air flow of the house that was modeled, holes were defined on each outward-facing wall (N, S, E, W) on both the upstairs and downstairs exterior walls. For the attic, holes were also defined on each exterior face. To allow air flow between the interior and the attic, a hole was 
defined in the attic floor. These three variables-leakage area from interior to outside, from attic to outside, and from interior to attic - are important in understanding how an unvented attic interacts with the interior space of a house and affects the moisture durability of the building components. The three variables were varied in the simulation matrix to better understand their effects.

Duct leakage was also characterized in the AFN by defining the whole forced-air system and defining leakage as a fraction of the maximum air flow and target zone. Two leaks were modeled in the ducts in the attic, a return leak and a supply leak. The supply leak flow rate was varied as one of the parameters in the simulation matrix.

The EMPD module was used to characterize the moisture buffering properties of the building components and interior mass. A custom EnergyPlus version was provided to ORNL by the National Renewable Energy Laboratory that incorporated a modified version of EMPD. This version incorporates two penetration depths, a short depth for short-term fluctuations in humidity and a longer depth for humidity changes with longer time constants ((Woods, Winkler et al. 2013). Because of the advanced nature of these two modules, the authors think this is the first time they have been combined in EnergyPlus to study the effects of an unvented attic on the indoor environment and on roof assembly durability.

\subsection{MODEL VALIDATION}

The model was validated against the measured interior environment of the research houses. Two variables were used to access the model uncertainty: the dry bulb temperature and the humidity ratio, which is the ratio of the mass of water in the air to the mass of dry air. These variables were investigated for both the interior and the attic zones. Figure 4 shows the hourly values of these variables when the model is run with actual 2010 weather and compared with the measured data for that year. Table 1 shows the modeling uncertainty for each variable in each zone. The coefficient of variation of the root-mean-squared error (CV-RMSE) and normal mean bias error (NMBE) are all under the acceptable limits in ASHRAE Guideline 14, which are $30 \%$ for CV-RMSE and 10\% for NMBE (ASHRAE 2002). These metrics give a good indication of the prediction uncertainty of the model. Better prediction uncertainty is indicated by lower values. 


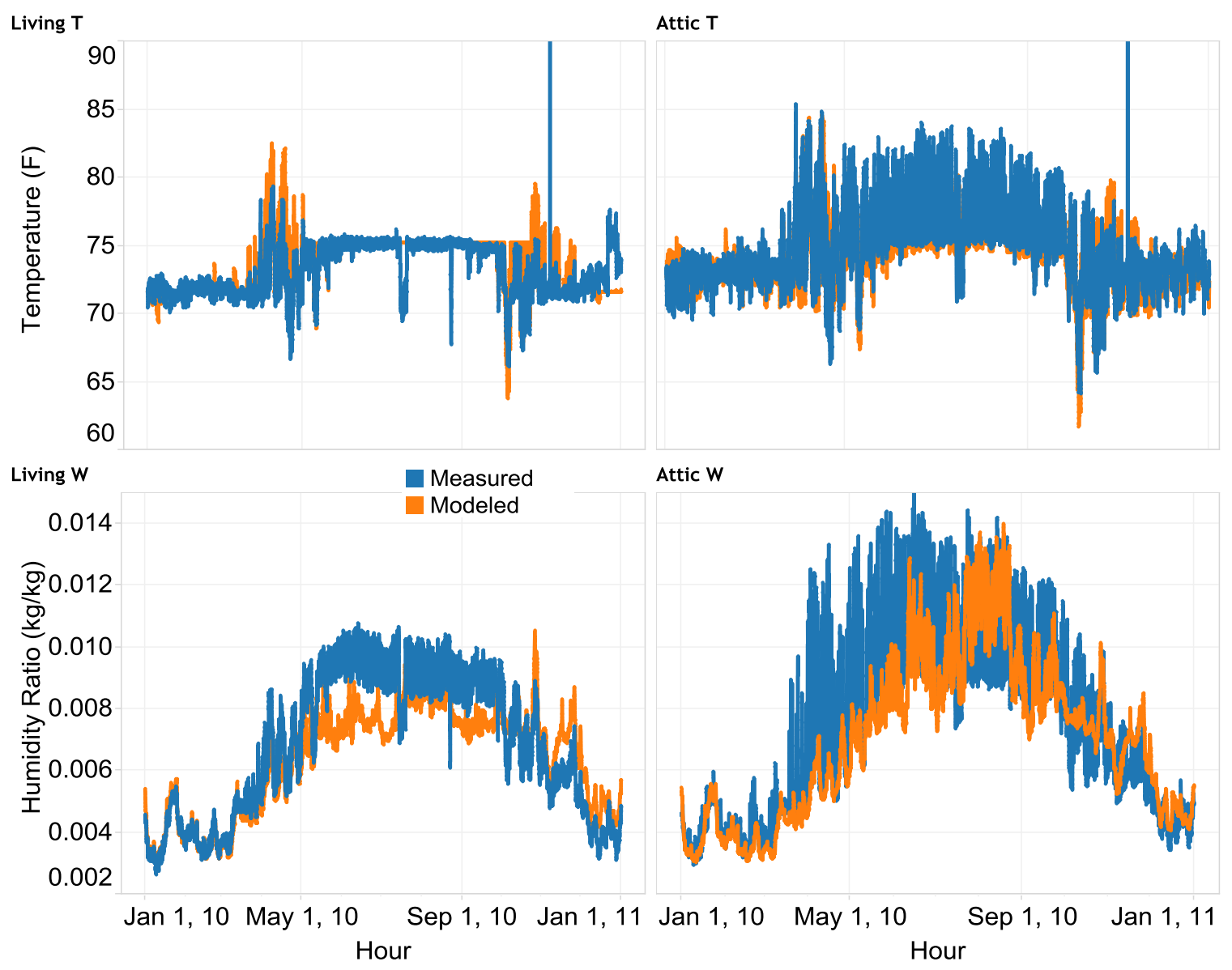

Fig. 4. The validated model output of zonal temperature and absolute humidity compared with measured data. Actual weather data were used in the model.

Table 1. Modeling uncertainty of the validated EnergyPlus model

\begin{tabular}{ccccc}
\hline & \multicolumn{2}{c}{ Temperature } & \multicolumn{2}{c}{ Humidity ratio } \\
\hline Zone & CV-RMSE & NMBE & CV-RMSE & NMBE \\
Living & $\pm 2 \%$ & $0 \%$ & $\pm 18 \%$ & $7 \%$ \\
Attic & $\pm 2 \%$ & $0 \%$ & $\pm 23 \%$ & $5 \%$ \\
\hline
\end{tabular}

CV-RMSE: coefficient of variation of the root-mean-squared error

NMBE: normal mean bias error

\subsection{TEST MATRIX}

To determine how the comfort level of the house and the moisture durability of the roof materials are affected by the unvented attic, a matrix of simulations was completed with five key inputs varied. These five inputs are expected to have the greatest impact on unvented attic performance, specifically its impact on the interior environment and the roof deck materials. They were chosen based on the researchers' previous work and experience. The variables are the leakage area of the living zone to the exterior, the leakage area of the attic zone to the exterior, the leakage area of the attic floor, the supply duct leakage flow rate to the attic, and the interior latent heat generation. To run all combinations of these variables required 486 simulations. In a small number of cases, the simulations did not complete because of an 
AFN error stating that the air flow was in the opposite direction from the expected direction. This error typically occurred when the supply duct leakage was 300 cubic feet per minute (CFM).

The following key input parameters and their values were used for the validation simulation of the test house.

- Leakage area-living to exterior

$62 \mathrm{in}^{2}$

- Leakage area - attic to exterior

$19.4 \mathrm{in}^{2}$

- Leakage area-attic floor

$108 \mathrm{in}^{2}$

- Supply leakage in attic

$11 \mathrm{CFM}$

- Total interior latent heat gain

$11 \mathrm{lb} /$ day

Most of these values serve as the mid-points of the test ranges presented in Table 2.

Table 2. Matrix values for simulation group

\begin{tabular}{|c|c|c|c|c|c|c|c|}
\hline & \multicolumn{2}{|c|}{ Low } & \multicolumn{2}{|c|}{ Medium } & \multicolumn{3}{|c|}{ High } \\
\hline $\begin{array}{l}\text { Leakage area-living to } \\
\text { exterior }\left(\text { in }^{2}\right)\end{array}$ & \multicolumn{2}{|c|}{39} & \multicolumn{2}{|c|}{82} & \multicolumn{3}{|c|}{148} \\
\hline $\begin{array}{l}\text { Leakage area-attic to } \\
\text { exterior }\left(\text { in }^{2}\right)\end{array}$ & \multicolumn{2}{|c|}{0} & \multicolumn{2}{|c|}{20} & \multicolumn{3}{|c|}{50} \\
\hline $\begin{array}{l}\text { Leakage area-attic floor } \\
\qquad\left(\mathrm{in}^{2}\right)\end{array}$ & \multicolumn{2}{|c|}{0} & \multicolumn{2}{|c|}{100} & \multicolumn{3}{|c|}{200} \\
\hline $\begin{array}{l}\text { Supply duct leakage in attic } \\
\text { (CFM) }\end{array}$ & 0 & 20 & 50 & 60 & 150 & & 300 \\
\hline $\begin{array}{l}\text { Total interior latent heat gain } \\
\text { (lb/day) }\end{array}$ & \multicolumn{2}{|c|}{11} & \multicolumn{2}{|c|}{28} & \multicolumn{3}{|c|}{45} \\
\hline
\end{tabular}

A blower door test conducted for the test house showed the whole house air change rate was 3.4 ACH50 and the effective leakage area was $80 \mathrm{in}^{2}$ (Sherman and Dickerhoff 1998). A guarded blower door test also indicated that $25 \%$ of the air leakage was through the attic. Therefore, based on these measurements, the test house leakage area was split, with $75 \%$ of the leakage attributed to the living space and the other $25 \%$ attributed to the attic space. These values were used as the median values in the test matrix. The supply leakage range used in the matrix is based on a maximum flow through the forced-air system of 1,200 CFM. So supply leaks of 0, 20, 50, 60, 150, and 300 CFM would result in attic supply duct leakage percentages of fan flow of $0,2,4,5,13$, and $25 \%$, respectively. Note that a 7 CFM return duct leakage was modeled for all iterations of the matrix. For the interior latent heat gain, an internal load with a 100\% latent fraction was modeled to add additional moisture to the living zone. The baseline case with no additional moisture provided a daily latent heat gain of about $11 \mathrm{lb}$. The medium latent gain case added $17 \mathrm{lb}$ of moisture to bring the total daily latent gain to $28 \mathrm{lb}$. The highest interior latent heat gain case added a total of $45 \mathrm{lb}$ of moisture per day to the space. Single family residences can range in their moisture generation output from $9-50 \mathrm{lb}$ depending on number of occupants among other variables (Christian, Trechsel 1994).

\subsection{WUFI SIMULATIONS}

EnergyPlus computations for the hourly air flow between the attic and exterior were read by WUFI1D to simulate the moisture content of the roofing materials. The drawing on the left in Fig. 5 illustrates the materials and thicknesses that were implemented in WUFI1D. 
The roof assembly was simulated with an air leakage between the attic and the exterior environment. Further, since the foam insulation material is expected to be airtight, no air is likely to travel through this material; so air will travel between the materials. The drawing on the right in Fig. 5 illustrates a possible air leakage path for air infiltration and exfiltration through the roof assembly. Since WUFI1D is a onedimensional calculation tool, the air leakage path had to be implemented as a point source. Depending on the direction of the air flow through the roof assembly, this source consisted of either indoor or outdoor air, and the magnitude of the source was based on the air flow rate calculated in EnergyPlus.
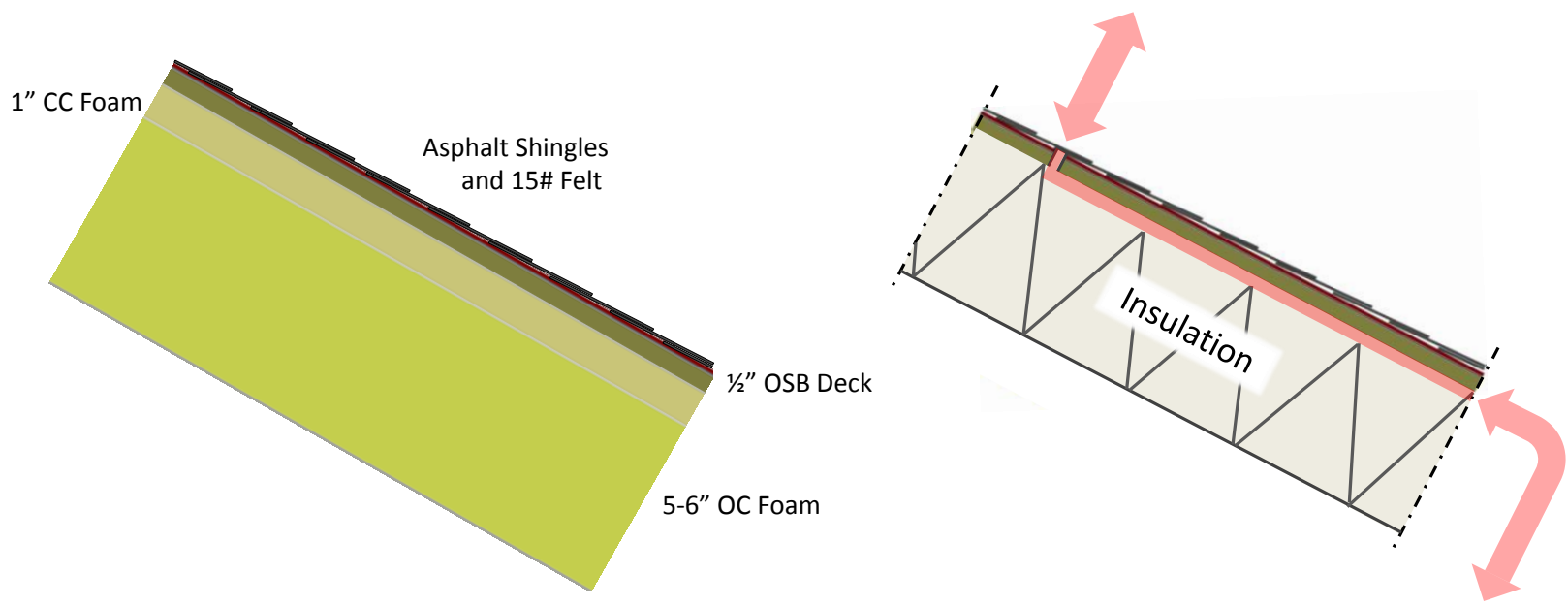

Fig. 5. The drawing at left illustrates the simulation model created in WUFI1D, representing the unvented attic roof assembly with its different materials and thicknesses. The drawing at right depicts the assumed air leakage path of air traveling through the roof assembly. The lower entrance/exit of air flow is assumed to exist in interfaces of the foam and wood structures.

\section{RESULTS AND DISCUSSION}

The simulation results were evaluated based on two performance indicators; the ASHRAE indoor comfort zone (ANSI/ASHRAE 2013) and the moisture durability of the roof assembly based on the risk of critical moisture levels in the roof sheathing.

For both performance indicators, each varying simulation parameter was studied and its influence on and sensitivity to the indicators was measured.

\subsection{ASHRAE COMFORT ZONE ANALYSIS}

Figure 6 illustrates a simplified psychrometric chart including the comfort zone boundaries defined in ANSI/ASHRAE Standard 55 (ANSI/ASHRAE 2013). According to the standard, an indoor climate with a temperature and air humidity within the comfort boundaries is declared as satisfying. Figure 6 also depicts all the hourly values of the simulated indoor climate conditions for the 411 simulated scenarios. Outliers exist above and to left of the defined comfort zone, but most are to the left. The reason most of the outliers are skewed to the left of the comfort zone is that some of the simulated scenarios resulted in an undersized HVAC system. Since the size of the HVAC system was the same in all simulations, when the leakage areas were very large the HVAC system could not meet the set point in the winter, resulting in the outliers to the left. 


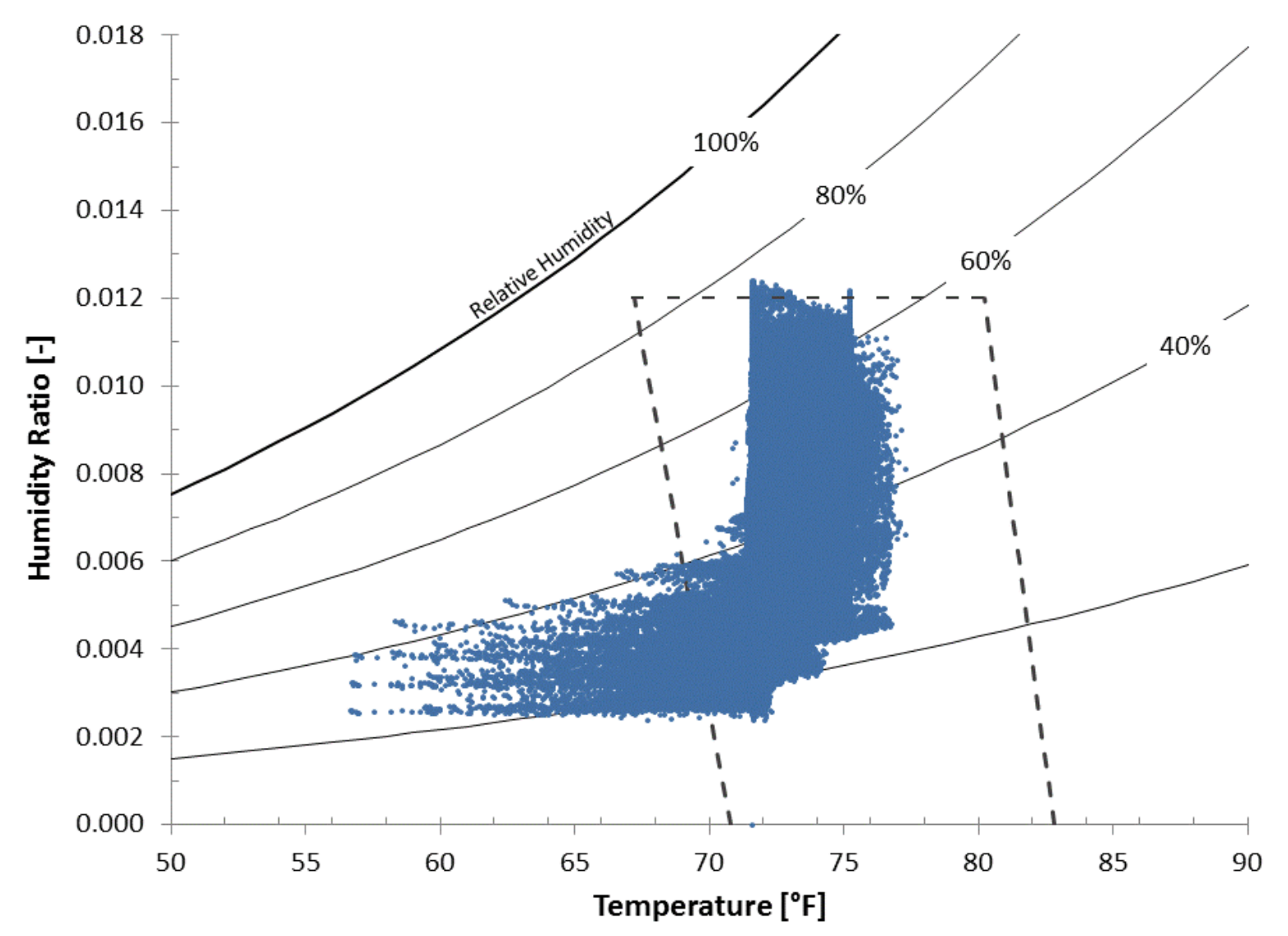

Fig, 6. ASHRAE Standard 55 defined comfort zone, including the simulated hourly indoor conditions for the 411 simulation scenarios. Most of the outliers are represented to the left side of the lower comfort boundary.

Figure 7 illustrates the outliers of four different simulation scenarios. The first scenario (red dots), represents the simulated scenario with the largest number of hours outside the comfort zone. This worst case has high air leakage rates between the indoors and the outdoors and between the attic and the outdoor environments. Further, the air leakage from the supply duct system is high for this worst-case scenario. Obviously, these conditions taxed the performance of the HVAC system, which is the reason for the large number of outliers in this simulation case. Figure 7 also presents the outliers of three additional scenarios. These three scenarios have the same values for the varying input parameters as does the worst case, except that one parameter value in each scenario is different. This allowed us to study the influence of each parameter on the indoor climate conditions. According to the results, a small air leak from the HVAC supply system (yellow dots) has the lowest impact, whereas both air leakage between the indoors and the outdoors (green dots) and between the attic and the outdoors (blue dots) has a large impact on the indoor climate conditions. This conclusion can be reached by looking at the increase in the outliers when a particular parameter is changed. 


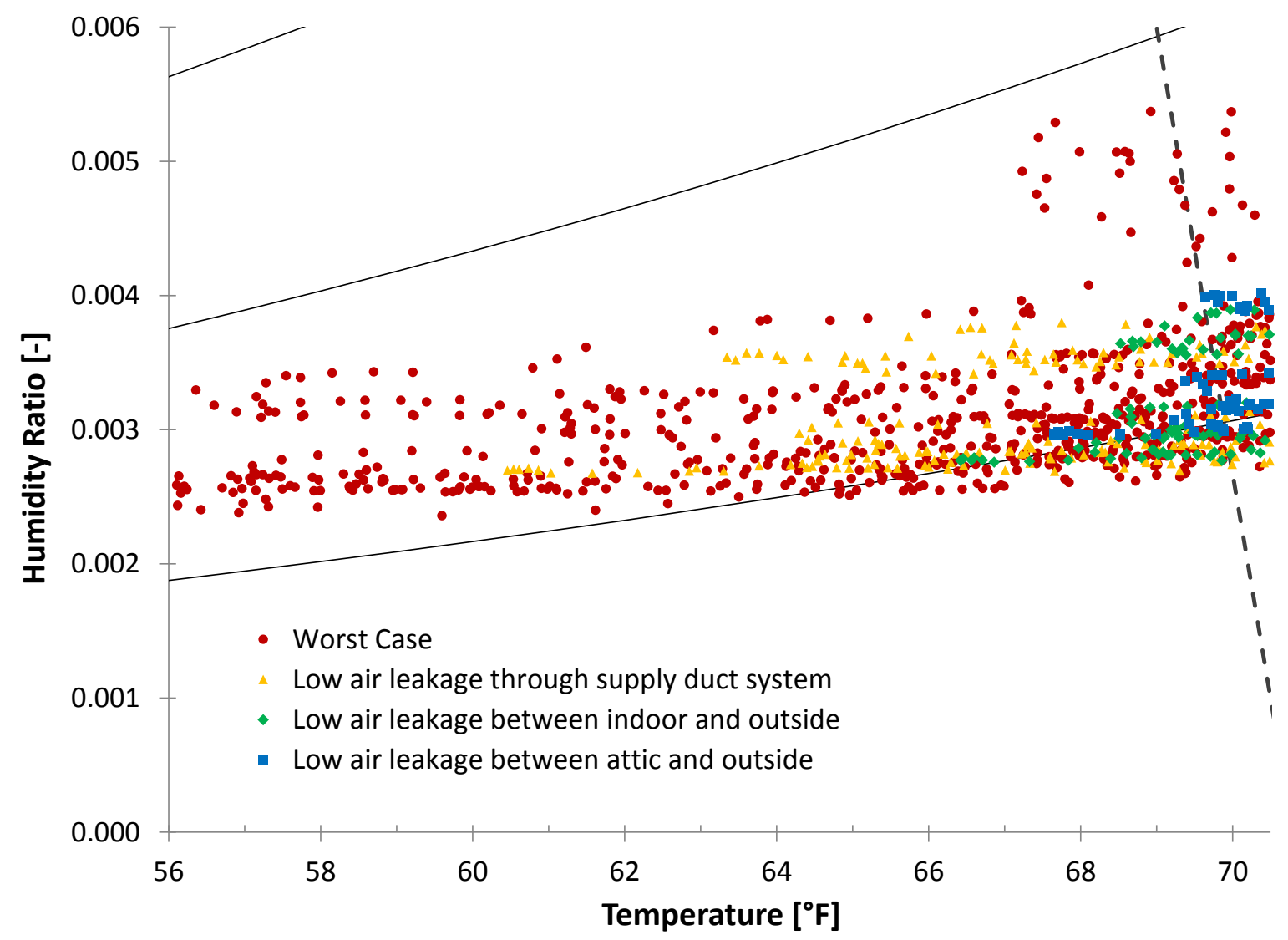

Fig. 7. The outliers of four simulation scenarios are presented. The red dots represent the worst case of all the completed simulations. This specific worst case simulation has over 600 hours outside the defined comfort zone annually. The three other scenarios represent simulations in which all the input parameters are the same as for the worst case, except for one parameter. This approach enabled us to study each parameter's influence. According to the results, reducing the air leakage from the HVAC supply duct system (yellow) helps to slightly reduce the number of outliers. A reduction of the air leakage through the building enclosure appears to be even more beneficial for the reduction of outliers (green and blue). The dashed line to the right of the chart represents the lower comfort zone boundary.

In addition, Fig. 7 serves as a parameter study of the indoor climate. However, this analysis is based only on four scenarios, which is why a sensitivity analysis based on all the simulated scenarios was conducted. Figure 8 is the result of that study and, as seen in Fig. 7, indicates that air leakage between the attic and the outdoor ambient has the highest impact on the indoor hygrothermal conditions. Air leakage from the supply duct system and air leakage between the indoors and outdoors also have large impacts on outliers to the left of the comfort zone, whereas indoor moisture generation and attic floor airtightness do not. The charts in Fig. 8 are presented as a ratio of parameter sensitivity. The parameter with the highest calculated influence receives a value of one, and the less influential parameters receive a value between zero and one, depending on their ratio of influence. 


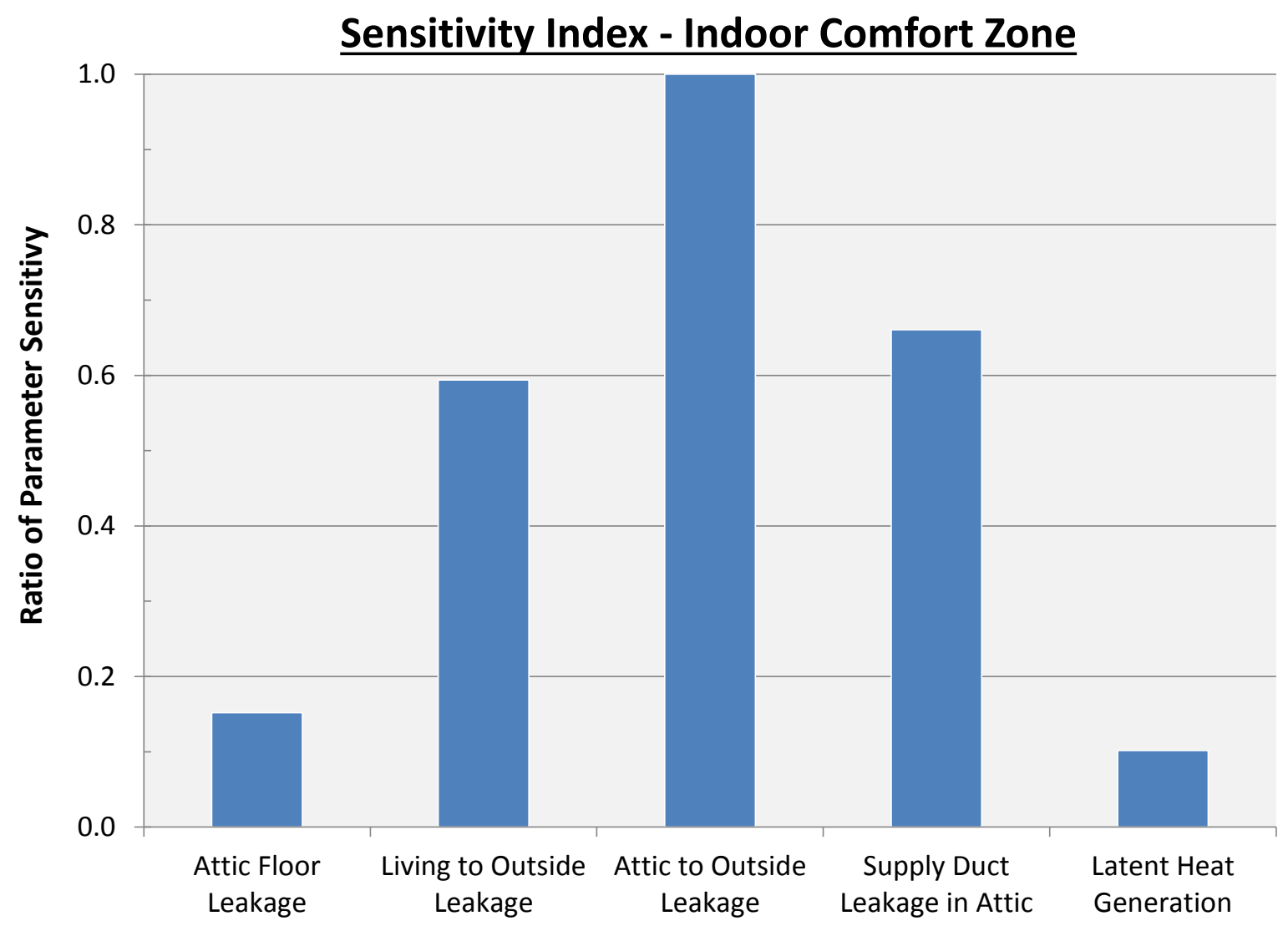

Fig. 8. A sensitivity analysis of the parameter influence on the outliers shows that air leakage between the attic and the outdoor environment has the highest impact on the number of hours with an indoor climate outside the defined comfort zone. The ratio values are relative; i.e., the parameter with the highest influence receives a value of one and the others receive a value either of one or lower, depending on their estimated sensitivity.

A range of annual hours outside the comfort zone for each simulation scenario is presented in Table 3 . These ranges create a performance pattern that helps clarify the impact of each parameter on the indoor temperature and humidity conditions. According to Table 3, the majority of simulated cases with a high number of comfort zone outliers are scenarios with a leaky building enclosure. The difference in the number of hours outside the comfort zone as the supply air leakage increases shows that the number of outliers increases accordingly. Air leakage through the attic floor seems to have an impact as well. This conclusion might seem obvious, since an attic floor with air leakage will enable air exchange between the attic and the indoor environment. If the roof also has air leakage, the outdoor conditions will have a higher impact on the indoor climate.

The analysis presented in Fig. 8 is mainly based on the outliers located to the left side of the comfort zone. However, outliers also exist that are within the acceptable temperature range but above acceptable air humidity levels, as seen in Fig. 6. These upper outliers are affected differently by the variations in parameter values, which is why a specific sensitivity analysis of the upper outliers is of interest. 
Table 3. The number of hours for each simulated case when indoor climate conditions are outside the ANSI/ASHRAE comfort zone. The table includes the five varying parameters and creates a performance pattern for them. The annual numbers of simulated hours outside the comfort zone varies from 0 to over 500 hours

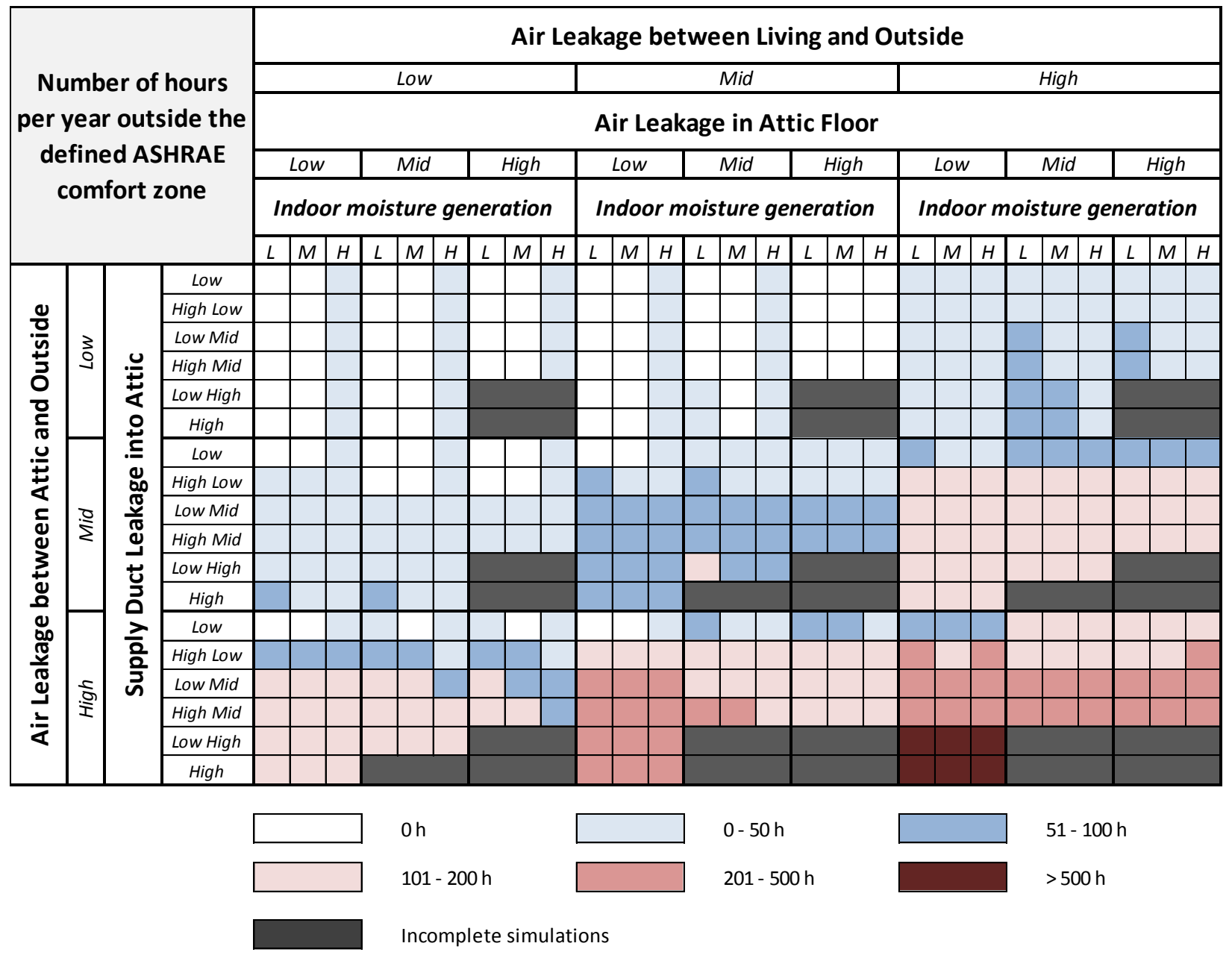

Figure 9 depicts the outliers of three different simulation scenarios with high humidity where the outliers are above the comfort zone: one worst-case scenario and two scenarios with the same input parameters as the worst case except one. This approach enabled us to study the impact of a change in one specific parameter value. In Fig. 9, the two chosen parameters evaluated are the air leakage rate between the attic and the outside, and the air leakage rate between the living space and the outside. According to the results, both parameters have a significant influence on indoor humidity levels.

The outliers presented in Fig. 9 indicate that air leakage from the indoors and the attic to the outdoors has positive impact on high indoor humidity outliers. According to Fig. 9, the number of outliers drops as the air leakage rate increases between the attic and the outdoors (blue) and between the indoors and the outdoors (green). However, there is one parameter with an even higher influence: the indoor moisture generation (latent heat). This is illustrated in Fig. 10, which clearly depicts how much the indoor humidity levels change with a decreasing indoor moisture generation rate. 


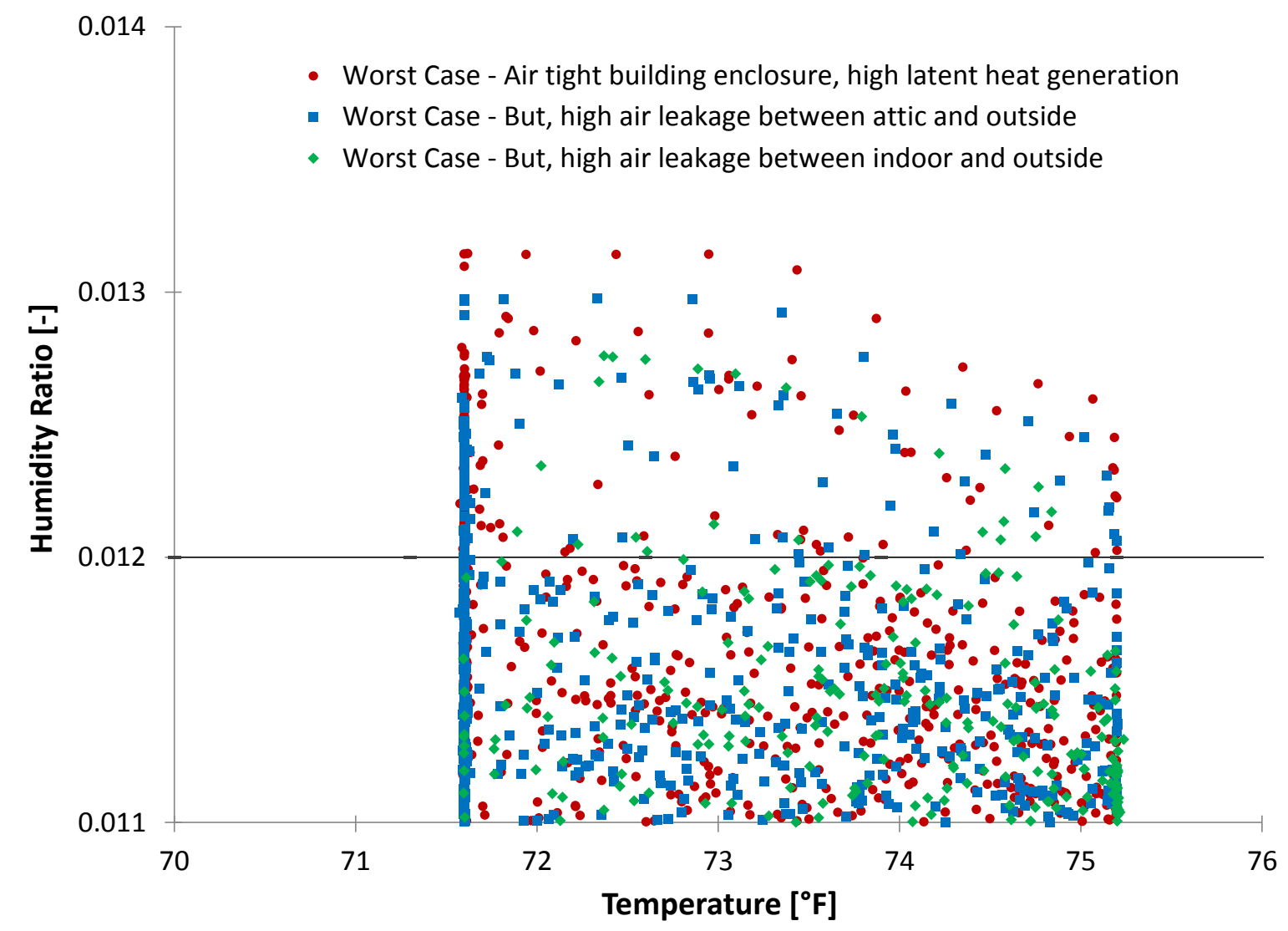

Fig. 9. The upper outliers of three simulation scenarios are presented. The red dots represent the worst case of all the completed simulations. The two other scenarios represent simulations in which the input parameters are the same as for the worst case except for one parameter. This approach enables the study of the influence of each parameter. According to the graph, air leakage between the living area and the outdoors (green) seems to have a higher impact on the humidity levels than air leakage between the attic and the outdoors (blue). The solid line represents the upper acceptable humidity level of the ASHRAE 55 comfort zone. 


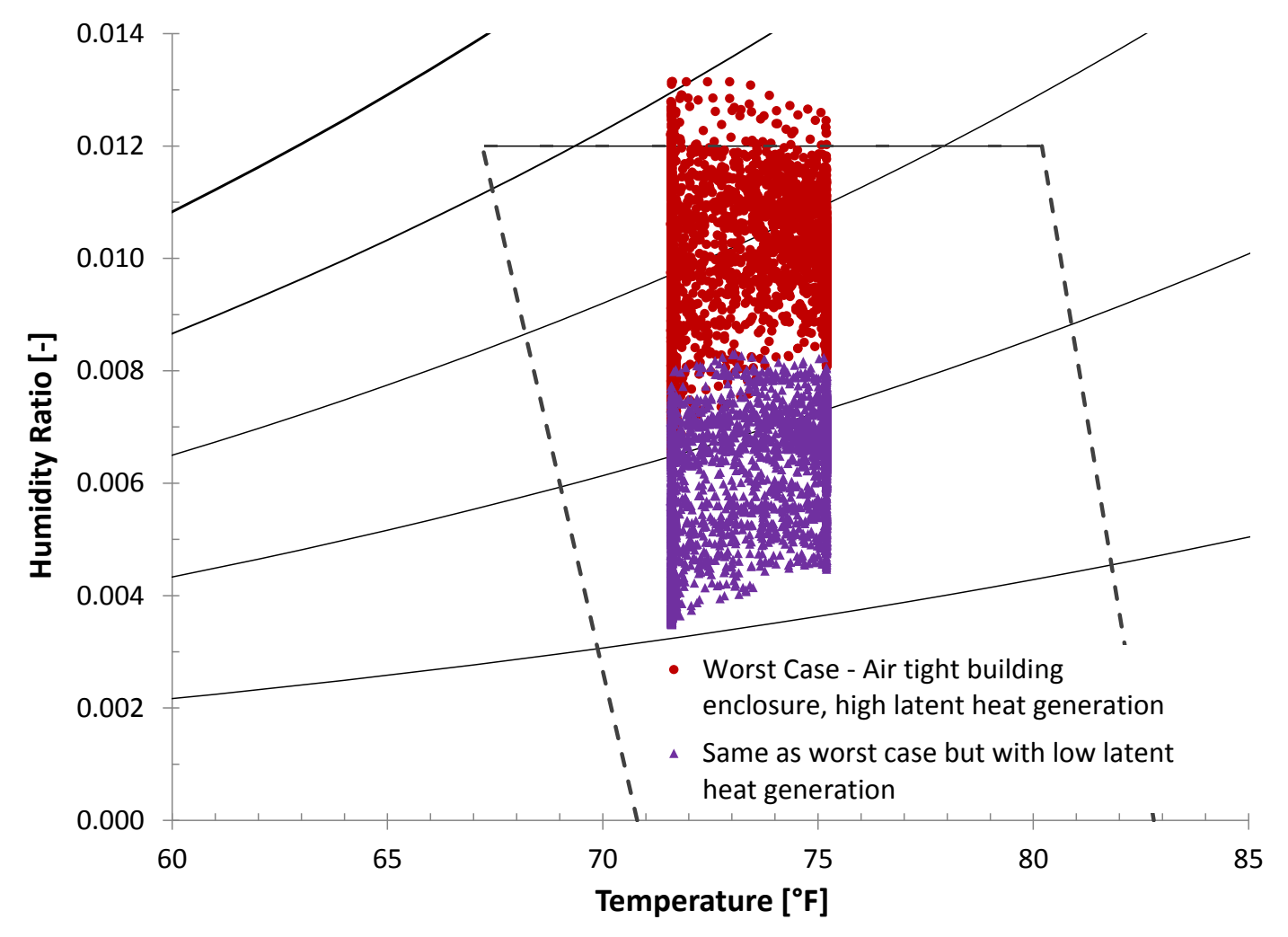

Fig. 10. A comparison between the worst-case scenario (red), which has a high indoor moisture generation rate, with a scenario with low indoor moisture generation. Clearly, the rate of indoor moisture generation has a significant impact on indoor humidity levels.

In addition to the evaluation of parameter influence based on individual simulation results (Figs. 9 and 10), an overall sensitivity analysis based on the complete simulation set is presented in Fig. 11. This analysis shows that indoor moisture generation has the largest impact. Air leakage between the indoors and outdoors affects the number of upper outliers, because the specific humidity on the outside influences humidity levels on the inside and affects the running cycle of the HVAC unit. The more the unit runs, the better the control of indoor moisture. Furthermore, when the air exchange between the house and the outdoors increases, the thermal load of the house rises and then the space-conditioning equipment runs longer. This in turn results in more moisture removed from the home. The opposite effect has been concluded to result in higher indoor humidity in air tight homes (Brown, Thornton et al. 2013).

Essentially the sensible heat ratio (SHR) of the equipment is now further from the SHR of the home. The SHR is the ratio of the sensible heat load to the total heat load (sensible plus latent). Similar phenomena exist as a result of air leakage between the attic and the outdoors, which is why this parameter has a high impact. 


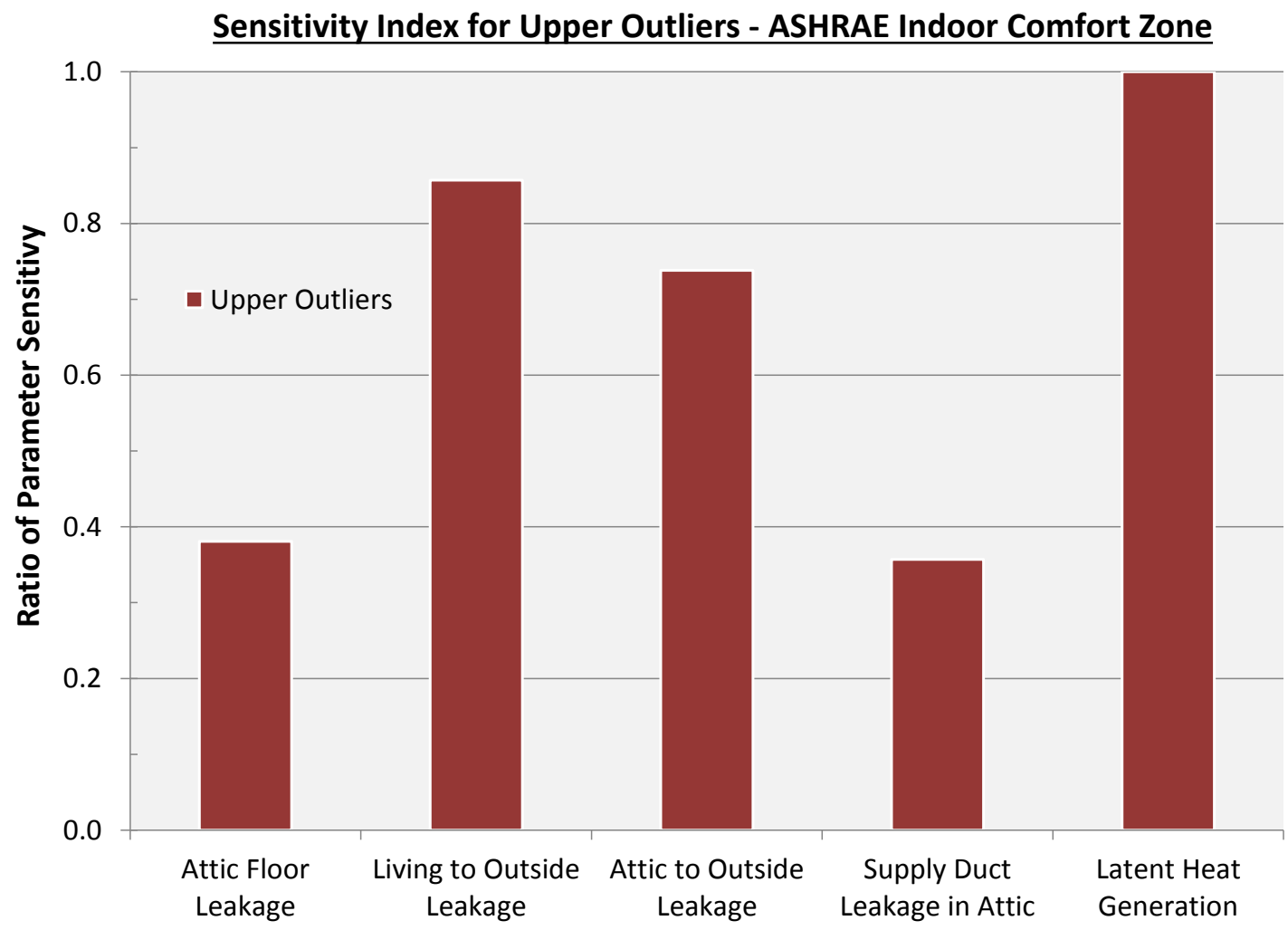

Fig. 11. A sensitivity analysis of the parameter influence on the upper outliers shows that air leakage through the building enclosure has the second largest impact on indoor humidity levels. The indoor moisture generation rate has the most influence on high interior moisture conditions. Air leakage through the building enclosure has such a high influence because outdoor humidity levels can either increase or decrease indoor humidity levels, and a building enclosure with more air leakage usually results in a larger energy penalty. This additional loss of conditioned air forces the HVAC unit to run more frequently, which subsequently better dehumidifies the supply air and thus affects indoor humidity levels. The sensitivity index values are relative; i.e., parameters with the highest influence receive a value of one and the others receive a value of one or lower, depending on their calculated sensitivity.

A performance pattern similar to the one seen in Table 3 is presented in Table 4, but this time only with respect to upper outliers (those involving high humidity levels). The most critical simulation scenarios associated with the risk of high humidity outliers are dominant when the indoor moisture generation is high and the building enclosure is relatively airtight. Since the risk of high humidity levels increases with increasing building airtightness, the humidity of the outdoor climate may effectively decrease the indoor humidity levels when they are outside the upper comfort zone. This finding is expected to be climate zone-specific and so is limited to the mixed-humid climate. According to Table 4, no high-humidity outliers exist with low or medium indoor moisture generation. High indoor moisture generation is required to exceed the upper humidity limit of the ASHRAE comfort zone. 
Table 4. The number of hours for each simulated case when the indoor climate conditions are outside the upper limits of the defined ANSI/ASHRAE comfort zone. The table includes the five varying parameters and creates a performance pattern for the indoor climate. The annual numbers of simulated hours outside the upper comfort zone limit vary between 0 to over 50 .

\begin{tabular}{|c|c|c|c|c|c|c|c|c|c|c|c|c|c|c|c|c|c|c|c|c|c|c|c|c|c|c|c|c|}
\hline \multirow{6}{*}{\multicolumn{4}{|c|}{$\begin{array}{l}\text { Number of hours } \\
\text { per year outside the } \\
\text { defined ASHRAE } \\
\text { comfort zone - } \\
\text { Upper outliers only }\end{array}$}} & \multicolumn{25}{|c|}{ Air Leakage between Living and Outside } \\
\hline & & & & \multicolumn{9}{|c|}{ Low } & \multicolumn{7}{|c|}{ Mid } & \multicolumn{9}{|c|}{ High } \\
\hline & & & & \multicolumn{25}{|c|}{ Air Leakage in Attic Floor } \\
\hline & & & & & Low & & & Mid & & & High & & & Low & & Mid & & Hig & igh & & Low & & & Mid & & & High & \\
\hline & & & & \multicolumn{9}{|c|}{ Indoor moisture generation } & \multicolumn{7}{|c|}{ Indoor moisture generation } & \multicolumn{9}{|c|}{ Indoor moisture generation } \\
\hline & & & & $L$ & $M$ & $H$ & $L$ & $M$ & $H$ & $L$ & $M$ & $H$ & $L$ & $M$ & $H$ & \begin{tabular}{l|l|}
$L$ & $M$ \\
\end{tabular} & $H$ & \begin{tabular}{l|l}
$L$ & $M$ \\
\end{tabular} & \begin{tabular}{l|l}
$M$ & $H$ \\
\end{tabular} & $L$ & $M$ & $H$ & $L$ & $M$ & $H$ & $L$ & $M$ & $H$ \\
\hline \multirow{18}{*}{ 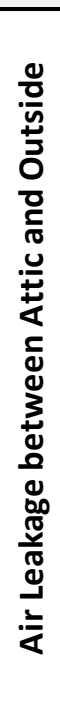 } & \multirow{12}{*}{ 30 } & \multirow{18}{*}{ 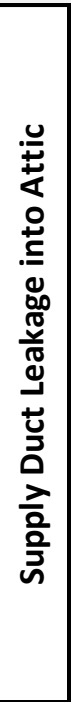 } & Low & & & & & & & & & & & & & & & & & & & & & & & & & \\
\hline & & & High Low & & & & & & & & & & & & & & & & & & & & & & & & & \\
\hline & & & Low Mid & & & & & & & & & & & & & & & & & & & & & & & & & \\
\hline & & & High Mid & & & & & & & & & & & & & & & & & & & & & & & & & \\
\hline & & & Low High & & & & & & & & & & & & & & & & & & & & & & & & & \\
\hline & & & High & & & & & & & & & & & & & & & & & & & & & & & & & \\
\hline & & & Low & & & & & & & & & & & & & & & & & & & & & & & & & \\
\hline & & & High Low & & & & & & & & & & & & & & & & & & & & & & & & & \\
\hline & & & Low Mid & & & & & & & & & & & & & & & & & & & & & & & & & \\
\hline & & & High Mid & & & & & & & & & & & & & & & & & & & & & & & & & \\
\hline & & & Low High & & & & & & & & & & & & & & & & & & & & & & & & & \\
\hline & & & High & & & & & & & & & & & & & & & & & & & & & & & & & \\
\hline & \multirow{6}{*}{ 옹 } & & Low & & & & & & & & & & & & & & & & & & & & & & & & & \\
\hline & & & High Low & & & & & & & & & & & & & & & & & & & & & & & & & \\
\hline & & & Low Mid & & & & & & & & & & & & & & & & & & & & & & & & & \\
\hline & & & High Mid & & & & & & & & & & & & & & & & & & & & & & & & & \\
\hline & & & Low High & & & & & & & & & & & & & & & & & & & & & & & & & \\
\hline & & & High & & & & & & & & & & & & & & & & & & & & & & & & & \\
\hline & & & & & & & & $\mathrm{Oh}$ & & & & & & & & $0-1$ & & & & & & & & $11-$ & $20 \mathrm{~h}$ & & & \\
\hline & & & & & & & & $21-$ & $30 \mathrm{~h}$ & & & & & & & $31-$ & $40 \mathrm{~h}$ & & & & & & & & $50 \mathrm{~h}$ & & & \\
\hline
\end{tabular}

\subsection{MOISTURE DURABILITY ASSESSMENT OF ROOF ASSEMBLY}

The second performance indicator of this report is the moisture durability of the roof assembly, which is relevant because structural failure due to moisture driven and accelerated decay has been observed in the wood sheathing of an unvented attic with spray foam insulation (Lstiburek 2006)

The moisture content of a wood material is considered an adequate indicator for evaluating the risk of accelerated types of decay such as rot. According to ASHRAE Fundamentals (ASHRAE 2013), a moisture content of $30 \%$ or more may result in structural failures due to decay. Even a local moisture content level as low as $20 \%$ must be considered a risk. These failure and risk levels have been adapted for this study and serve as performance criteria for the simulated moisture content levels of the roof assembly.

A total of 411 simulation scenarios were completed in EnergyPlus. These 411 scenarios generated 411 different attic climates that were used as attic boundary conditions for the roof assembly in WUFI1D simulations. The purpose of using WUFI1D was to analyze the hygrothermal performance of the roof assembly and study the risk of critical moisture levels in the wooden sheathing. 
An analysis of the hygrothermal performance of a roof assembly must include moisture transfer mechanisms. Typically, the two most influential mechanisms are water vapor diffusion and convection. The latter is usually the hardest to predict; hence, it will depend on a number of uncertainties such as air pressure differences and geometrical properties. However, it is crucial to incorporate convection into a hygrothermal analysis, because air can rapidly move moisture and energy from and to different spaces and materials. Consequently, convection may heat or cool down the materials surrounding the air leakage path in which it travels, and it may also dry or wet the very same materials. If the conditions are favorable for doing so, air leakage can deposit moisture on intermediate surfaces and thus effectively increase the moisture content of the surface layer of materials. Basically, air leakage paths can be divided into two different paths, a direct path and a diffusive path (see Fig. 12). The direct path is mainly an energy leak, whereas the indirect air leakage path affects the moisture conditions of the surrounding materials more significantly. A direct path usually does not cause moisture problems, since the materials surrounding the air leakage path reach temperatures similar to the temperatures of the entering air (Künzel, Zirkelbach et al. 2011)and so keep temperatures in the air leakage path above the dewpoint of the air. An indirect air leakage path however, transports air over a more complex air leakage path and with a relatively lower air flow rate than in a direct path. Therefore, the exchange of energy becomes less efficient and allows for the materials to reach the dewpoint temperature of the air.
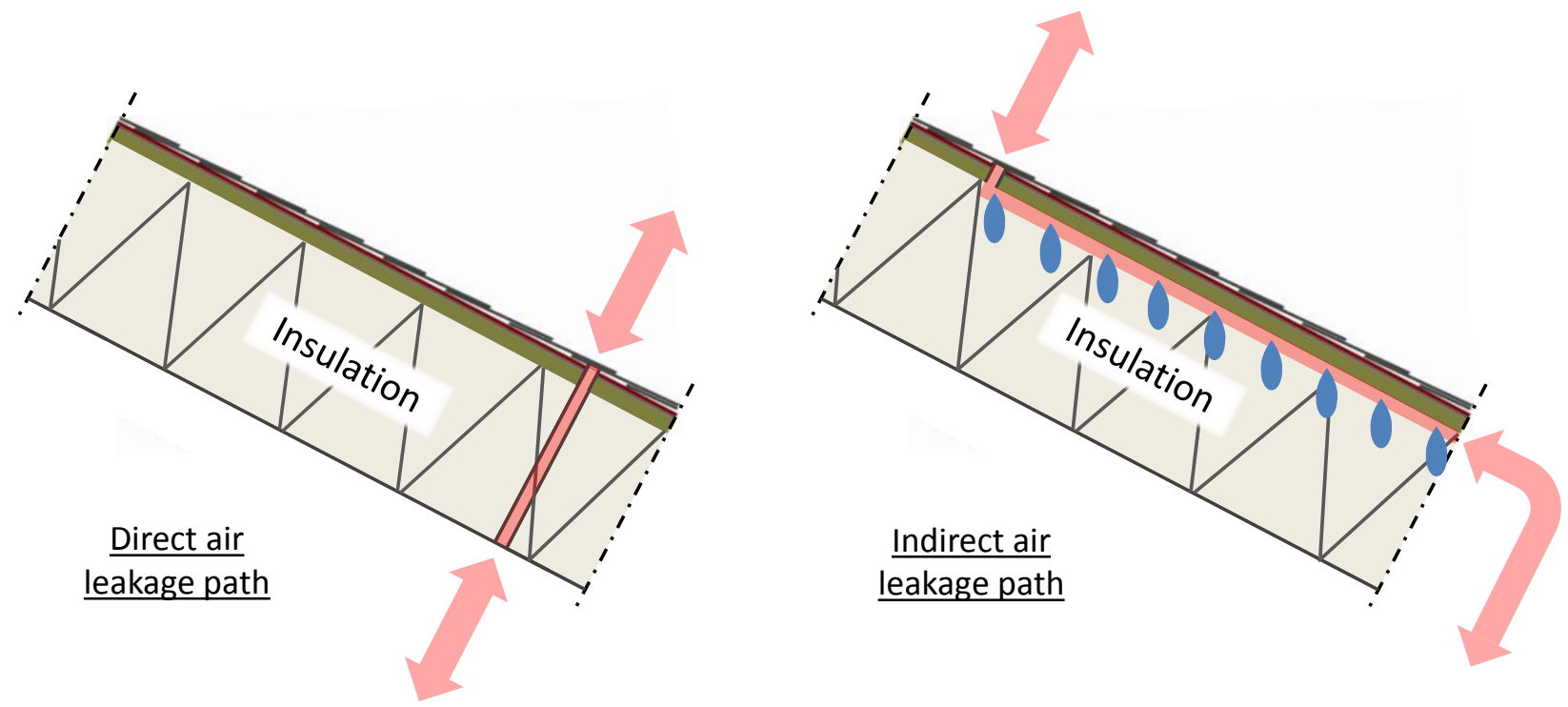

Fig. 12. The air leakage path through the components of the building enclosure can be defined as a direct or an indirect air leakage path. The direct path is mainly an energy leak, whereas the indirect path has more potential to affect the moisture performance of the components. The arrow located on the right side of the indirect path indicates that interior air may enter or exit the air leakage path at a point not illustrated by the drawing.

Since the air flow rate through an indirect air leakage path is lower than the flow rate through a direct path, there is a peak in the air flow rate where the risk of critical moisture levels exists. As seen in Fig. 13, the location of the peak is related to the air flow rate, whereas its magnitude is related to the vapor pressure difference between the surface material of the air leakage path and the inflowing air. Figure 13 shows that the higher the vapor pressure difference, the higher the humidity peak. Figure 13 and its shape is affected by parameters other than air flow rates and vapor pressure gradients; it is also affected by the material properties such as thermal heat capacity, conductivity, and thermal diffusivity as well as moisture storage capacity, vapor and liquid diffusivity, and other vapor transportation mechanisms. 


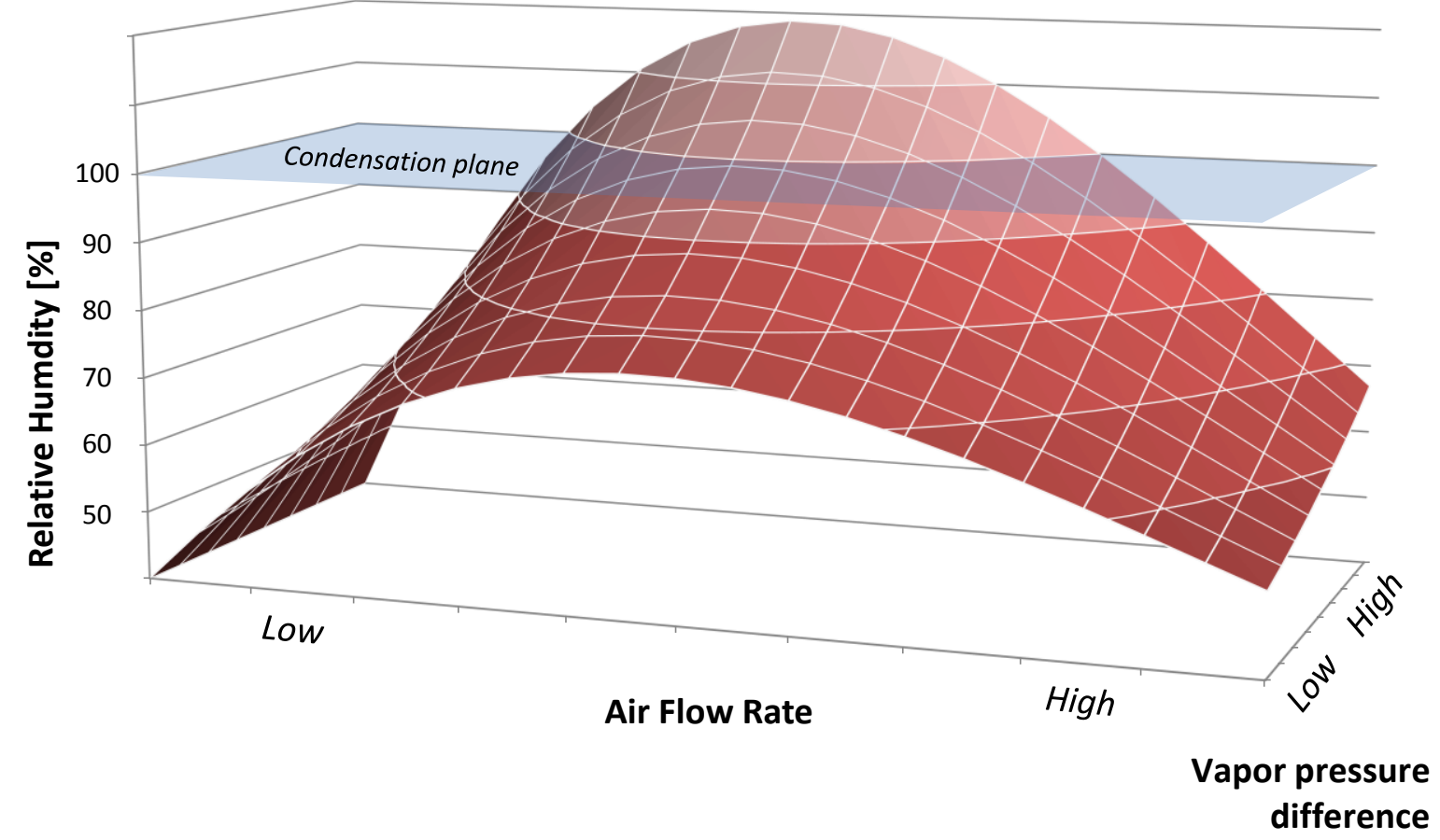

Fig. 13. The relative humidity of the surface material of an air leakage path is affected by the hygrothermal conditions of the inflowing air. The higher the air flow rate, the closer the temperature and moisture conditions become to those of the inflowing air. If the air flow rate is not sufficiently high, the exchange of heat might not be sufficient to increase the surface material temperature beyond the dewpoint of the inflowing air, thus resulting in condensation. An even lower air flow rate is not sufficient to substantially increase the vapor pressure of the air leakage path. The vapor pressure gradient between the incoming air and the surface material inside the air leakage path will also influence the magnitude of the critical moisture peak. If the vapor pressure gradient is low, no critical humidity level is reached, although with increasing vapor gradient, the maximum humidity level increases as well. In reality, the relative humidity will not exceed $100 \%$; instead, a condensation plane illustrates when condensation occurs.

The phenomenon of a critical moisture peak has been seen in previous study (Ojanen and Kumaran 1996), and is further illustrated in Fig. 14. In this illustration, two hygrothermal states are defined, one for the inflowing air and one for the surface material of the air leakage path (before any air leakage is initiated). Depending on the air flow rate, the routes vary toward a final equilibrium state. With a small air flow rate, the thermal exchange is minor, though if the dewpoint temperature of the traveling air is higher than the surface temperature of the air leakage path, condensation will occur. When the air flow rate increases, moisture is more effectively condensed at the surface until the heat exchange forces the surface temperature to rise above the dewpoint. After this point, an increased air flow rate will further raise the surface temperature and thus the conditions of the air leakage path will move toward that of the inflowing air; i.e., the air leakage path will become an energy leak and therefore the air leakage will not be as large a risk for moisture-dependent material degradation. Again, Fig. 14 represents an arbitrary pattern of the effect of air leakages through a building component, and it is still very much affected by parameters other than air flow rates and vapor pressure gradients. 


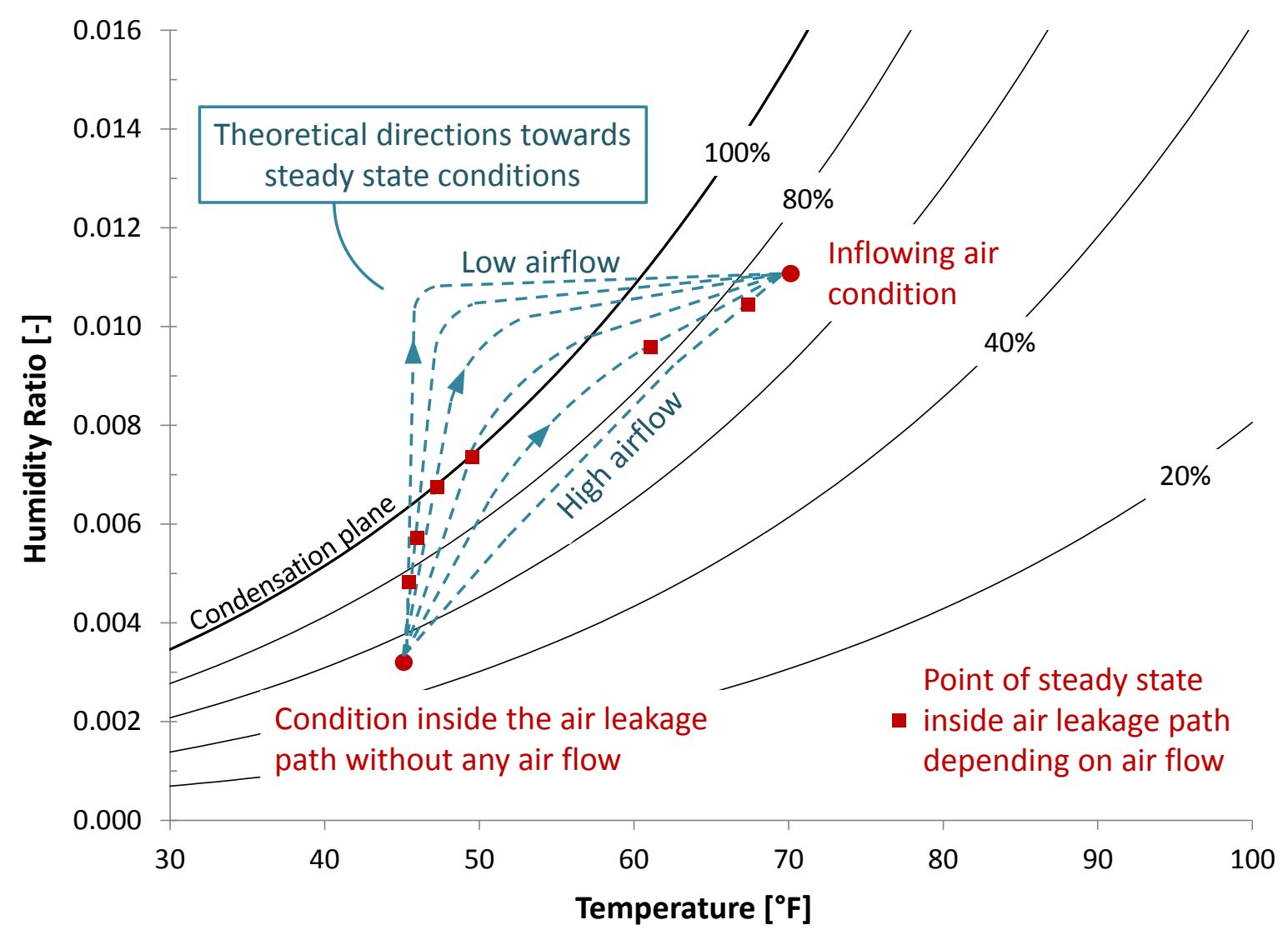

Fig. 14. The phenomenon of a critical moisture peak when air leaks through a component of the building enclosure is illustrated in a psychrometric chart. The red dots represent the initial hygrothermal states of the inflowing air and that of the surface material of the air leakage path. The more the air flow rate increases, the more the equilibrium state of the air leakage path moves toward that of the inflowing air. This is illustrated through the dashed lines, which represent the theoretical directions in which the conditions inside the air leakage path move toward a steady state at a particular air flow rate. However, if the vapor pressure of the air leakage path increases faster than the temperature, vapor from the inflowing air may condense on the air leakage surface material as a result. These points of equilibrium states are illustrated with square symbols; when they are situated on the 100\% relative humidity graph, condensation occurs. The points of equilibrium are arbitrarily chosen and only serve to explain why condensation may not exist with low and high air leakage rates but may exist with mediate air leakage rates.

The results of simulating the 411 scenarios in WUFI prove that the phenomenon described in Figs. 12 to 14 exists. It is further discussed in the following paragraphs. 

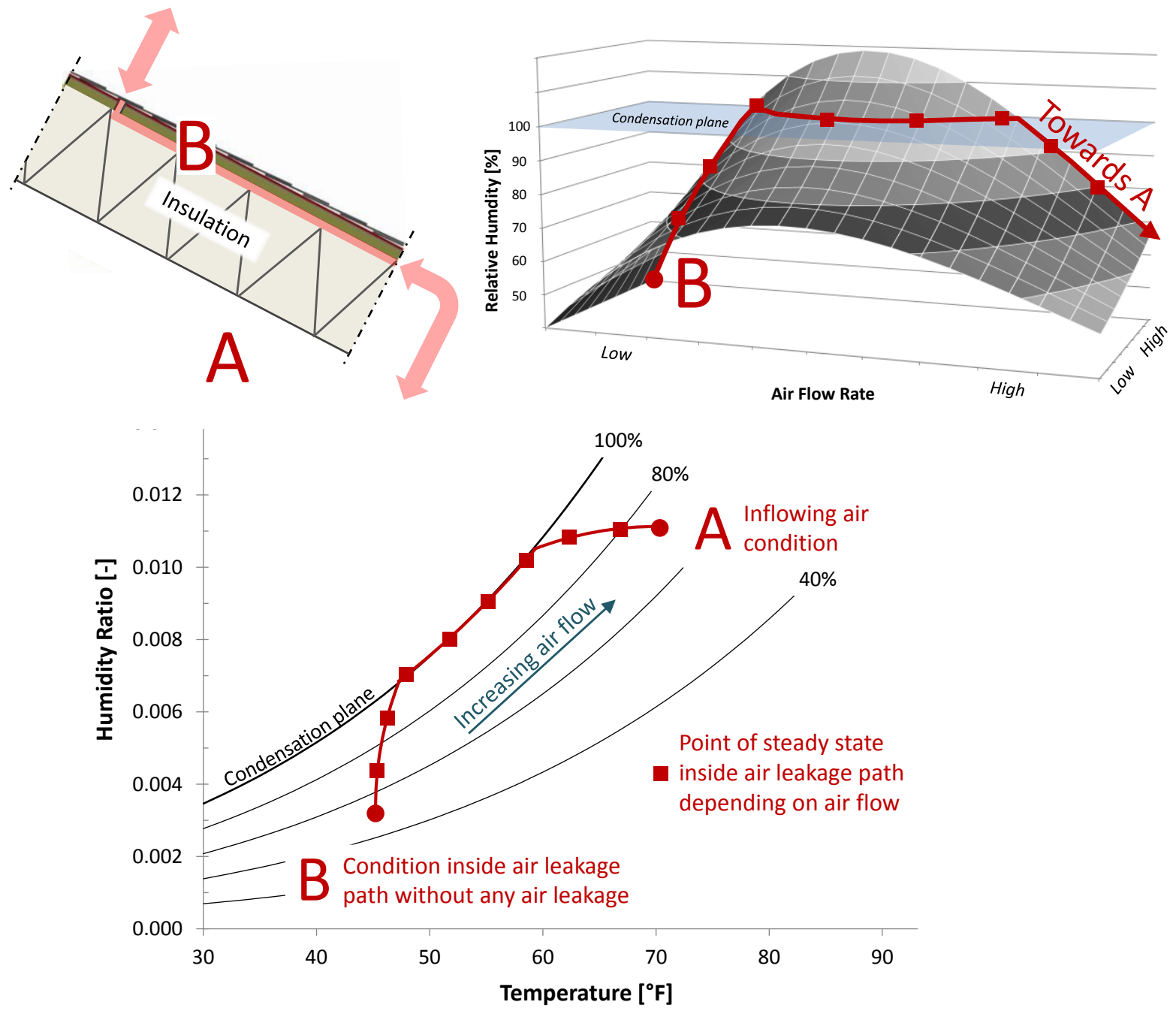

Fig. 15. An overview of the described critical moisture peak depicts the phenomenon illustrated in Fig. 12-Fig. 14. B defines the hygrothermal condition inside the air leakage path when no air flow exists and A defines the condition of the inflowing air.

Tables 5-7 represent the risk of reaching critical moisture levels in the wood sheathing under the simulated conditions. According to ASHRAE Fundamentals (ASHRAE 2013), a moisture content of 30\% or more may result in structural failure due to decay, although a local moisture content level as low as $20 \%$ must be considered a risk. Therefore, in Tables 5-7, moisture contents below $20 \%$ are marked in green (safe), moisture contents between 20 and 25\% in orange (risk), and moisture contents close to or greater than $30 \%$ in red (expected failure). Table 5 represents the simulation result with a low indoor moisture generation rate. As seen in Table 5, in that scenario, there are no simulated cases in which the moisture content of the wooden sheathing reaches notable levels. 
Table 5. The maximum moisture content of the wooden roof sheathing does not reach a critical level when simulated with a low indoor moisture generation rate

\begin{tabular}{|c|c|c|c|c|c|c|c|c|c|c|c|c|}
\hline \multirow{3}{*}{\multicolumn{4}{|c|}{$\begin{array}{l}\text { Low Daily Moisture } \\
\text { Generation - } 11 \text { lbs }\end{array}$}} & \multicolumn{9}{|c|}{ Air Leakage between Living and Outside } \\
\hline & & & & \multicolumn{3}{|c|}{ Low } & \multicolumn{3}{|c|}{ Mid } & \multicolumn{3}{|c|}{ High } \\
\hline & & & & \multicolumn{9}{|c|}{ Air Leakage in Attic Floor } \\
\hline & & & & Low & Mid & High & Low & Mid & High & Low & Mid & High \\
\hline \multirow{18}{*}{ 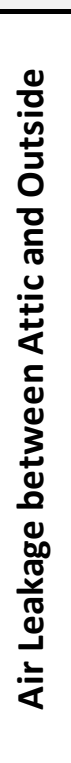 } & \multirow{6}{*}{ క్ } & \multirow{18}{*}{ 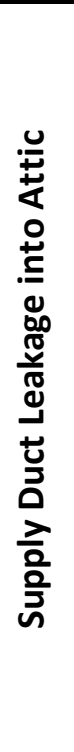 } & Low & & & & & & & & & \\
\hline & & & High Low & & & & & & & & & \\
\hline & & & Low Mid & & & & & & & & & \\
\hline & & & High Mid & & & & & & & & & \\
\hline & & & Low High & & & & & & & & & \\
\hline & & & High & & & & & & & & & \\
\hline & \multirow{12}{*}{$\mid \begin{array}{l}\text {.5 } \\
\text { : }\end{array}$} & & Low & & & & & & & & & \\
\hline & & & High Low & & & & & & & & & \\
\hline & & & Low Mid & & & & & & & & & \\
\hline & & & High Mid & & & & & & & & & \\
\hline & & & Low High & & & & & & & & & \\
\hline & & & High & & & & & & & & & \\
\hline & & & Low & & & & & & & & & \\
\hline & & & High Low & & & & & & & & & \\
\hline & & & Low Mid & & & & & & & & & \\
\hline & & & High Mid & & & & & & & & & \\
\hline & & & Low High & & & & & & & & & \\
\hline & & & High & & & & & & & & & \\
\hline & & & & & Safe & & & Risky & & & Failure & \\
\hline
\end{tabular}

Table 6 however, starts to indicate performance pattern and parameters that have a high influence on the risk of critical moisture levels. The results of Table 6 illustrate the maximum moisture contents from simulations made with an assumed mediate indoor moisture generation rate. As has been illustrated in Figs. 12-14, critical moisture contents exist somewhere between low and high air leakage rates through the roof assembly. According to Table 6, the only cases with maximum moisture contents above $20 \%$ exist when the air leakage rate is simulated as mediate. Neither low nor high air leakage rates generate risky levels. Further, Table 6 shows that an airtight building enclosure between the indoor environment and the outside results in a higher risk of critical moisture levels during the winter. The reason this phenomenon is seen is that the outdoor climate has a drying effect on the indoor climate under the simulated conditions and climate zone in the winter. Therefore, more critical cases exist when the exchange of air between the interior and exterior is low. 
Table 6. Maximum moisture content levels reach risky levels when the air leakage between the indoor and outdoor environment is low and when air leakage rates through the roof assembly are simulated as mediate. The table represents the performance pattern of simulated cases with a mediate moisture generation of $28 \mathrm{lb}$ per day.

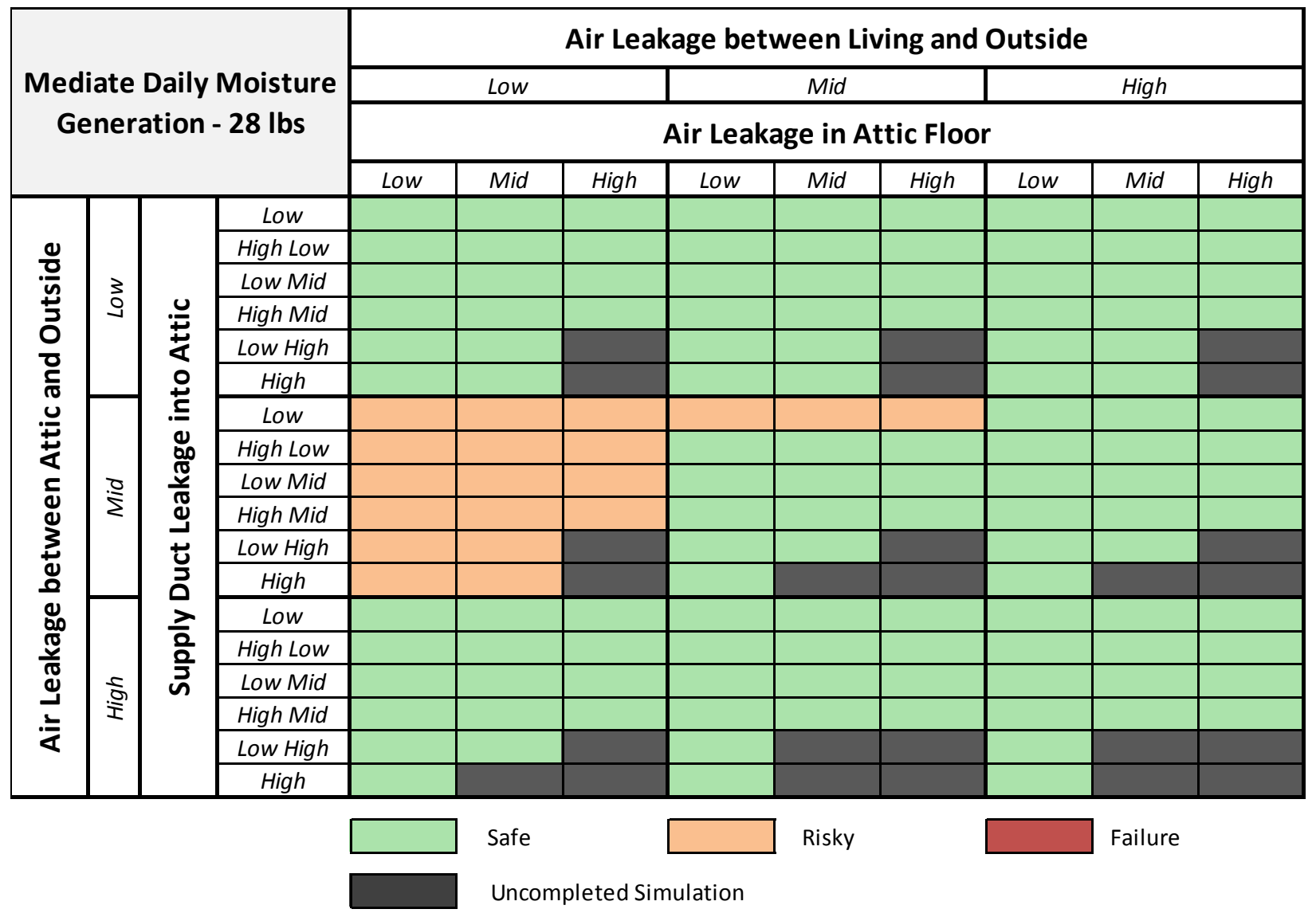

In Table 7, the discussed performance pattern becomes even clearer. No critical moisture levels exist when the roof assembly is simulated as being airtight i.e. perfectly sealed attic. In addition to what was seen in Table 6, another parameter seems to have a slight impact. Looking at the performance pattern in Table 7, the attic floor has a positive impact on the moisture performance of the wooden sheathing if it is an air leakage path. This conclusion might be perceived as contradicting what the rest of the performance pattern is indicating, i.e., that indoor humidity, including the attic environment, is the major moisture source in the air leakage path of the roof assembly. However, a low air leakage rate through the attic floor is less likely to promote a higher moisture level in the wood sheathing because the simulated air flow direction is generally downward and not upward. If the air leakage were upward, it would increase the risk of moisture collection in the wood sheathing. The direction of the air flow through the attic floor is mainly a result of the predefined simulation conditions of the HVAC system and the pressure gradient over the attic floor and corresponds well to measured data (Boudreaux, Pallin et al. 2013).

What is also seen in Table 7 is that whether the supply duct system is leaky does not significantly affect the climate of the attic and thus the moisture durability of the wooden sheathing. These simulation results show that creating a moisture-safe attic environment by adding a supply and return duct to the attic space is not an appropriate measure to improve the roof moisture durability. The highest moisture levels of the wooden sheathing occur during the winter, as seen in Figure 16 and Figure 17. Therefore, the moisture 
durability will not benefit from the dehumidifying effect of the HVAC system since the critical moisture levels do not exist when the HVAC system is running in cooling mode.

Table 7. Maximum moisture contents of the simulated cases with an assumed high rate of indoor moisture generation. Apparently, a critical moisture peak exists for simulated scenarios with a mediate air leakage rate through the roof assembly. In addition, if the air leakage rate between the indoor and outdoor environment is low, there is a risk of reaching a moisture level in the wood sheathing that should be associated with an expected failure

\begin{tabular}{|c|c|c|c|c|c|c|c|c|c|c|c|c|}
\hline \multirow{3}{*}{\multicolumn{4}{|c|}{$\begin{array}{l}\text { High Daily Moisture } \\
\text { Generation - } 45 \text { Ibs }\end{array}$}} & \multicolumn{9}{|c|}{ Air Leakage between Living and Outside } \\
\hline & & & & \multicolumn{3}{|c|}{ Low } & \multicolumn{3}{|c|}{ Mid } & \multicolumn{3}{|c|}{ High } \\
\hline & & & & \multicolumn{9}{|c|}{ Air Leakage in Attic Floor } \\
\hline & & & & Low & Mid & High & Low & Mid & High & Low & Mid & High \\
\hline \multirow{18}{*}{ 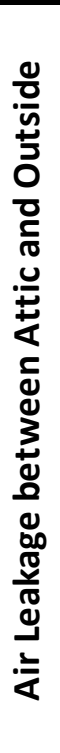 } & \multirow{6}{*}{ ב్ } & \multirow{6}{*}{ 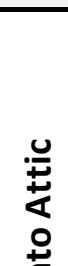 } & Low & & & & & & & & & \\
\hline & & & High Low & & & & & & & & & \\
\hline & & & Low Mid & & & & & & & & & \\
\hline & & & High Mid & & & & & & & & & \\
\hline & & & Low High & & & & & & & & & \\
\hline & & & High & & & & & & & & & \\
\hline & \multirow{6}{*}{$\stackrel{?}{\Sigma}$} & \multirow{11}{*}{ 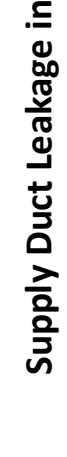 } & Low & $29.0 \%$ & $29.4 \%$ & & & & & & & \\
\hline & & & High Low & $30.0 \%$ & $29.0 \%$ & & & & & & & \\
\hline & & & Low Mid & $29.8 \%$ & & & & & & & & \\
\hline & & & High Mid & $29.7 \%$ & & & & & & & & \\
\hline & & & Low High & $29.5 \%$ & & & & & & & & \\
\hline & & & High & $29.4 \%$ & & & & & & & & \\
\hline & \multirow{6}{*}{ 疍 } & & Low & & & & & & & & & \\
\hline & & & High Low & & & & & & & & & \\
\hline & & & Low Mid & & & & & & & & & \\
\hline & & & High Mid & & & & & & & & & \\
\hline & & & Low High & & & & & & & & & \\
\hline & & & High & & & & & & & & & \\
\hline & & & & & Safe & & & Risky & & & Failure & \\
\hline
\end{tabular}

The influence from the varying parameters was further studied by looking at variations in moisture content when the value of one parameter is changed. Fig. 16 shows the simulated variation in average moisture content of the wooden sheathing for three simulation scenarios with varying air leakage rates between the attic and the outdoor environment. These three scenarios are also depicted in Table 8. As seen in Fig. 16, the maximum moisture content is the highest for the simulation scenario with a mediate air leakage rate between the attic and the outside; this finding confirms the performance pattern seen in Table 7.

Fig. 17 shows the results of a study similar to that illustrated in Fig. 16. However, this time the varying input parameter is the air leakage rate between the living space and the outdoor environment. As was seen in Table 7, the maximum average moisture content of the wooden sheathing decreases with an increasing air leakage rate. The reason for this is that the exterior environment has a drying effect (Knoxville, TN, Climate Zone 4) on the interior; thus the higher the air exchange rate is between these two environments, the more significant the drying effect becomes. Since the indoor environment affects the attic climate, the moisture content of the roof assembly is affected as well. The chosen simulation scenarios are also presented in Table 8 . 


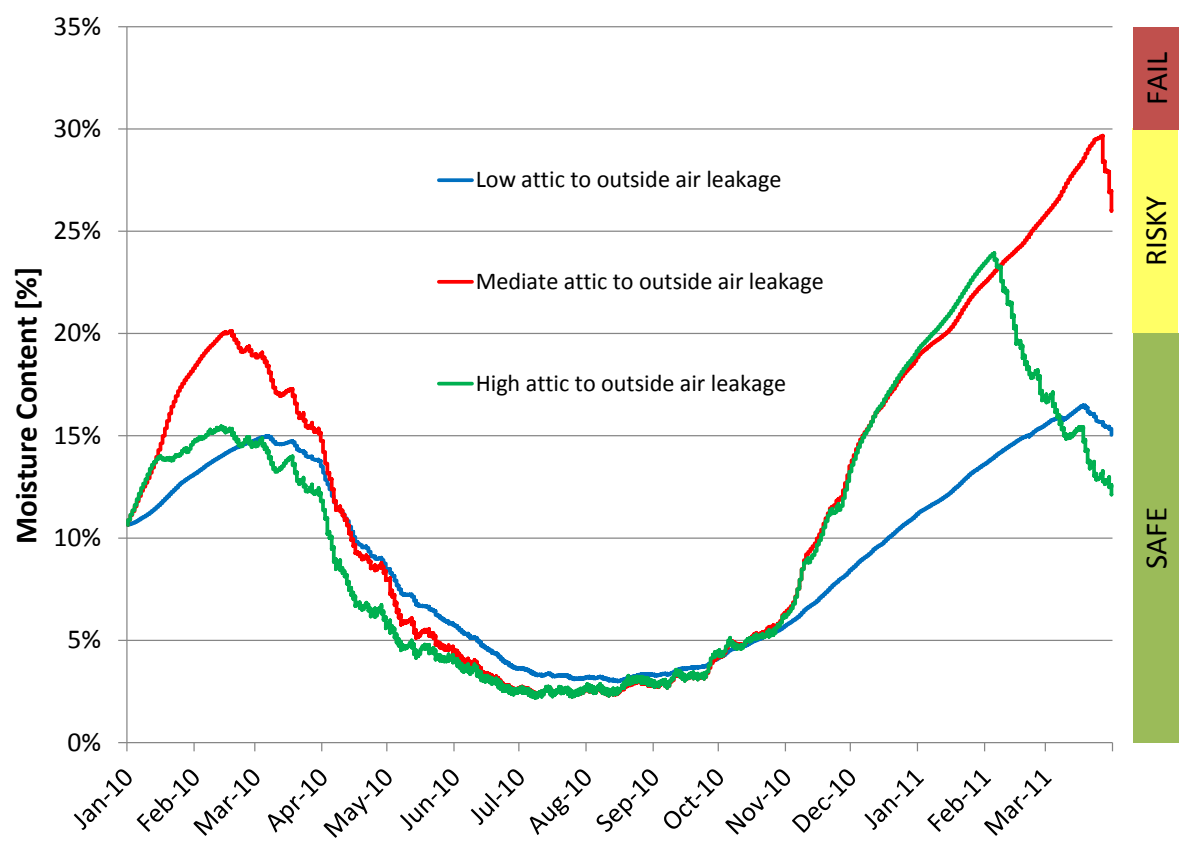

Fig. 16. The variation in average moisture content of the wooden sheathing is presented for three different simulation scenarios with a low, mediate, and high air leakage rate between the attic and the exterior environment. Apparently, the simulated scenario with a mediate air leakage rate generates the highest maximum of the three studied

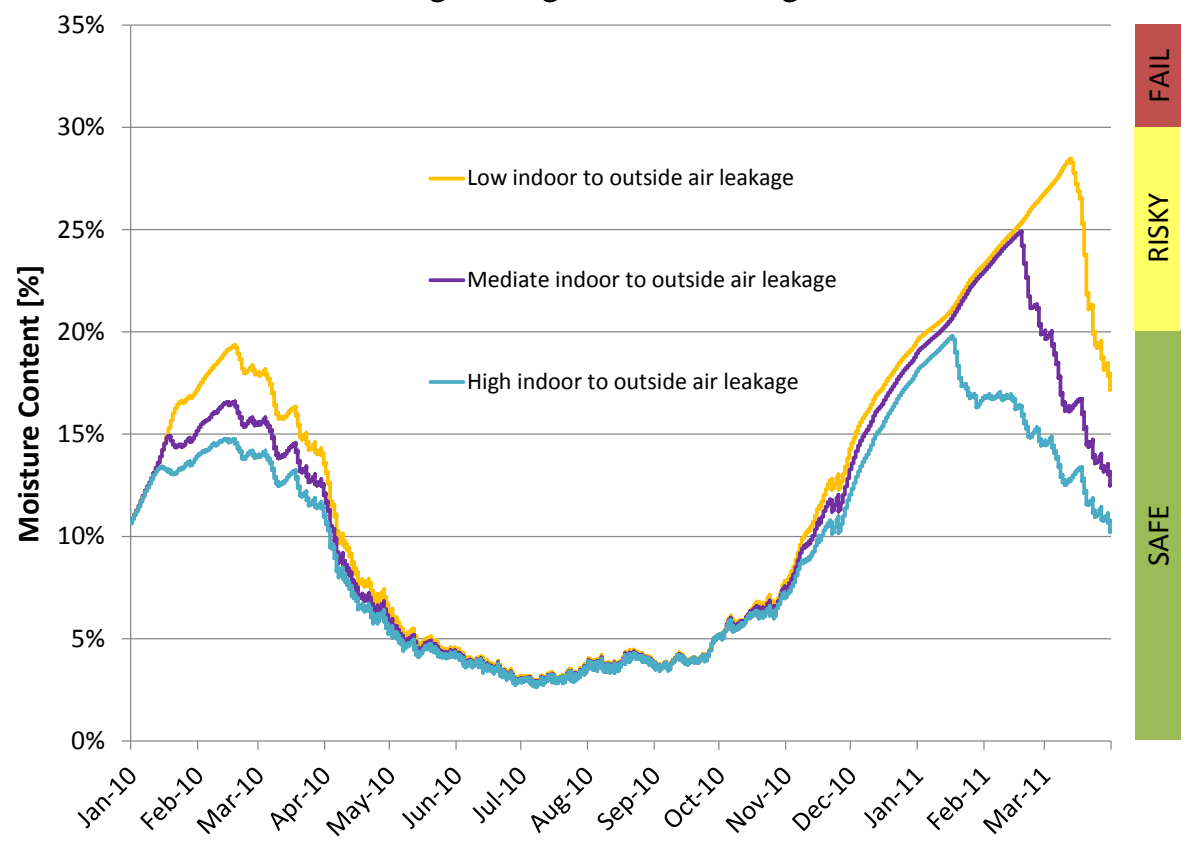

cases.

Fig. 17. The variation in average moisture content of the wooden sheathing is presented for three different simulation scenarios with a low, mediate, and high air leakage rate between the indoor and the outdoor environments. Apparently, the outdoor environment has a drying effect on the interior, which subsequently has a drying effect on the attic climate and thus the moisture content of the wooden sheathing. 
Table 8. The six simulation scenarios represented in Figs. 16 and 17 are presented and marked with colors that represents those used in Figs. 16 and 17

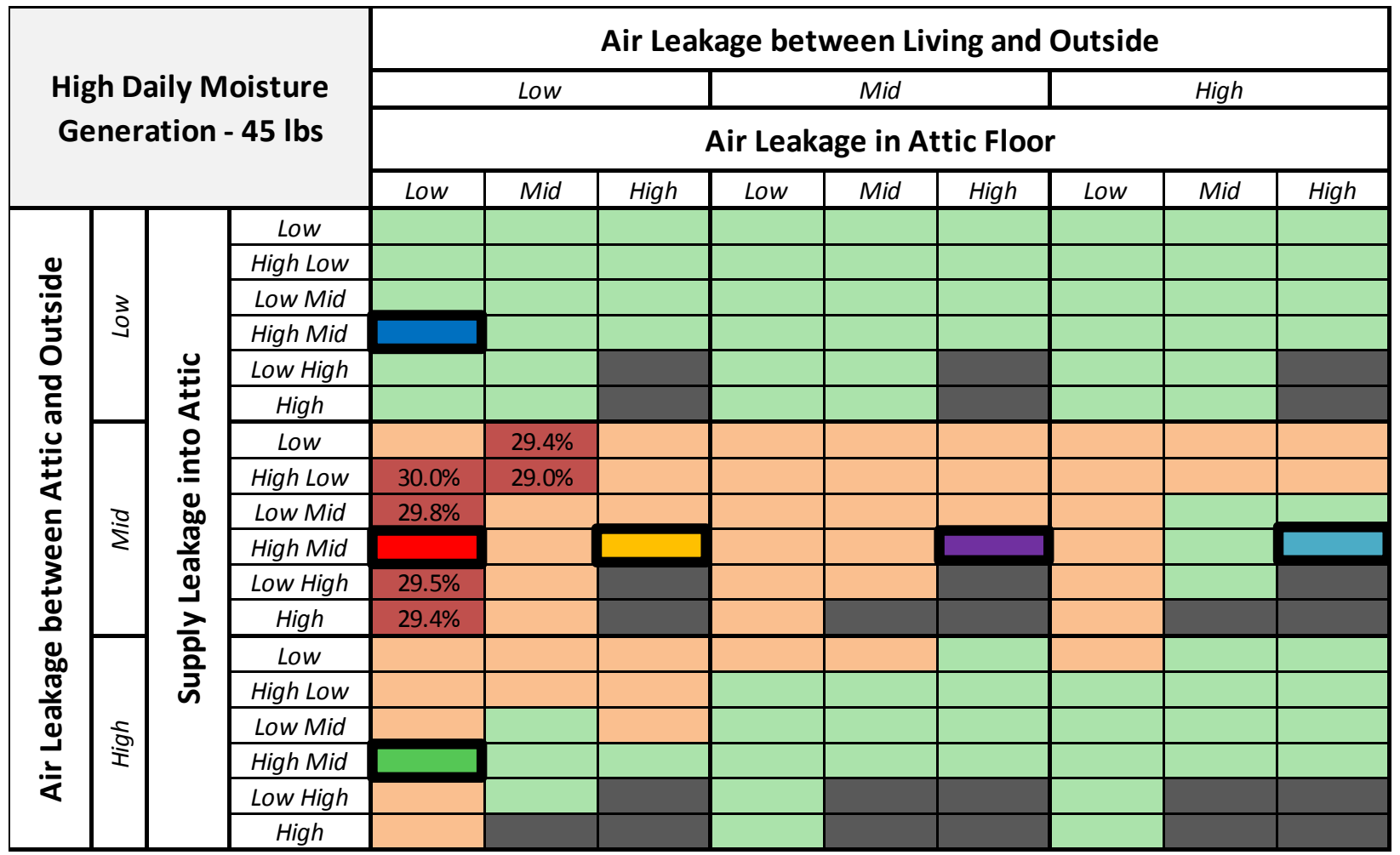

A final effort was made to study the impact of the varying parameters of this study through a sensitivity analysis. Figure 18 shows the results of the analysis, which indicate that the two most influential parameters for the moisture durability of the wood sheathing are the indoor moisture generation rate and the air leakage rate through the roof assembly. The airtightness of the building enclosure between the interior and exterior environments also has a fairly strong influence, which was also seen in Fig. 17. The least influential parameter is the airtightness of the attic floor.

In general, the air flow rate through the roof assembly is directed upward for the simulated scenarios. Therefore, it is obvious that the attic/indoor environment may impact the simulated air leakage path more than the outdoor environment does. The direction of the air flow is affected by a number of air pressure gradients, such as the gradients over the roof assembly, the attic floor, the indoor/outdoor environments, the supply/return duct systems, and the attic. Consequently, a varition in one of these pressure gradients will have an impact on all the others. That is why an inward air flow direction through that roof assembly must be expected to exist as well. In a cold or a mixed climate, an overall inward air flow might have a drying effect on the roof assembly, whereas a wetting effect can be expected in a hot and humid climate. 


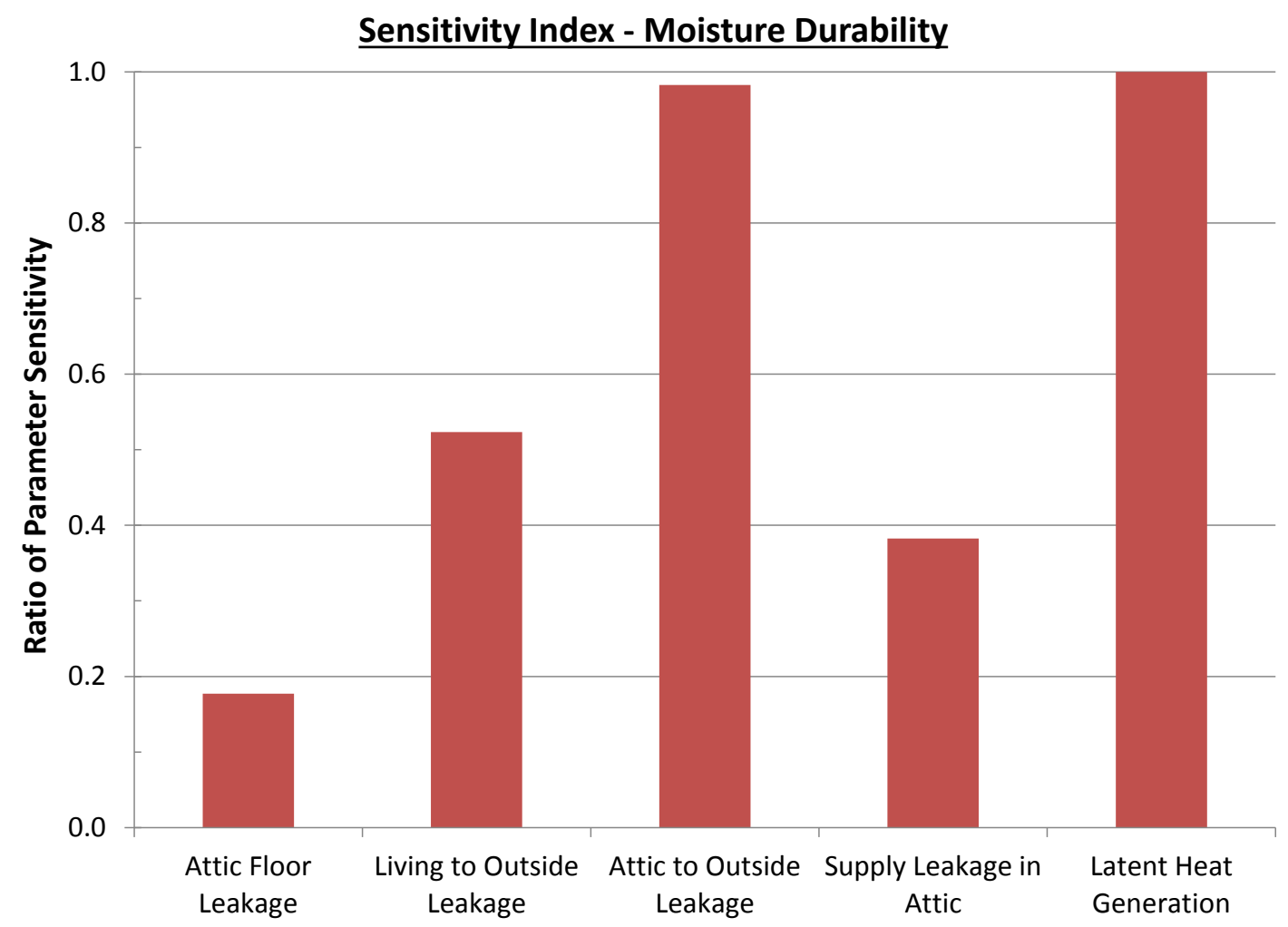

Fig. 18. A sensitivity analysis of the influence of five varying input parameters on the moisture content of the wood sheathing shows that indoor moisture generation rate and the air leakage rate through the roof assembly (air leakage path) have the highest impact. The air leakage rate between the indoor and outdoor environment has a relatively large impact as well, but the air leakage through the attic floor does not. The parameter with the highest calculated influence receives a value of one and the less influential parameters receive a value between zero and one depending on their ratio of influence.

\section{CONCLUSION}

In this study, a research team at ORNL investigated the indoor comfort and the roof moisture durability of residential houses with unvented attics in a mixed-humid climate. The conclusions to be stated are limited to the simulated climate and not necessarily applicable to others.

Through 411 simulations, five different input variables were evaluated with regard to the previously defined performance indicators of indoor comfort and roof assembly moisture durability. These five variables were chosen based on their potentially large influence on the indoor comfort and roof moisture durability. The five variables were used as input parameters in the simulation models with a range of predefined values. The five input parameters assumed to have a strong influence on the performance indicators were airtightness of the attic floor, airtightness of the building enclosure between the indoor and outdoor environments (walls), airtightness of the roof construction, air leakage from the HVAC supply duct system, and indoor latent heat (moisture) generation.

The indoor climate of the simulation scenarios was evaluated based on a standardized indoor comfort zone (ANSI/ASHRAE 2013). To estimate the influence of the varying input parameters, the number of hours with an indoor climate outside the comfort zone (outliers) was calculated for each simulation case. These outliers were mostly at low temperatures, meaning the simulated indoor temperature was below the 
lower comfort zone boundary. An analysis of these lower outliers showed that they were mainly the results of air leakage through the building enclosure (roof and walls), but also the results of a leaky supply duct system. In general, the existence of the lower outliers was a result of an undersized HVAC system in relation to the airtightness of the building enclosure. In addition to the lower outliers, there were outliers above the upper humidity limit (humidity ratio $>0.012$ ). These outliers were naturally more influenced by indoor moisture generation, although the airtightness of the building enclosure had a high impact as well.

The moisture durability of the unvented attic roof construction was studied through 411 WUFI1D simulations in which the moisture content of the wood sheathing acted as a performance indicator. Guidelines for critical moisture content levels in wood-based materials (ASHRAE 2013) were used as criteria for the performance evaluation. According to the results, air leakage through building components is likely to have the highest impact on roof material moisture durability at relatively mediate air flow rates. For the simulated scenarios in the mixed-humid climate, a high air flow rate is more beneficial for moisture safety because the temperature and moisture conditions of the air leakage path will come closer to those of the climate from which the air originates. An analysis of the parameter influence shows that air leakage between the attic and the outdoors has a large impact on the hygrothermal performance of the roof when an air leakage is simulated. Indoor moisture generation has a slightly higher impact on moisture durability, and together with the air leakage through the roof, these two parameters are by far the most influential variables.

As seen in this study, the supply and return of a moderate amount of conditioned air only slightly decreases the humidity levels in attic space. Therefore, a supply and a return of conditioned air into the attic space make little difference in roof moisture durability in the mixed-humid climate. This conclusion is quite reasonable since the highest moisture levels in the sheathing occur during the winter in a mixedhumid climate, which is also the time when there is no dehumidifying effect from the HVAC system. A comparison can be made with a crawl space where instead the most moisture critical time is during the summer and thus a supply and return of conditioned air will have a dehumidifying effect when it's needed.

In conclusion, the overall airtightness of the building enclosure and indoor moisture supply have the highest impact on both the indoor climate and the moisture durability of an unvented attic roof construction. In addition, the moisture durability of the roof construction is very sensitive to air leakage rates that are not high enough to substantially affect the temperatures in the air leakage pathway through which it travels. In a cold or a mixed climate, air leakage through the roof from the inside will function as a moisture source; therefore, a pressure gradient that induces exfiltration of attic air through the roof construction should be avoided in an unvented attic. The opposite is valid in a hot and humid climate. In such a climate, air movement downward from the outdoors toward the attic space must be avoided because the outdoor climate will function as a moisture source. Generally speaking, if an unvented attic roof assembly with wood sheathing is not very airtight, the moisture durability of the roof might be at risk. Therefore, it is crucial to determine the overall pressure gradient over the roof assembly and to take action accordingly to ensure that air is not traveling in an unwanted direction.

Based on the research presented, it seems best in a mixed-humid climate to make the envelope of a house with an unvented attic as tight as possible (to reduce energy consumption) and control the interior moisture generation to less than $30 \mathrm{lb} /$ day. This would avoid a risky environment for the roof assembly from a moisture durability standpoint. If moisture generation level cannot be maintained at or below that level, then the energy savings due to the unvented attic will be less because it will be necessary to use more energy to maintain indoor comfort. Adding a supply duct to the attic can remedy indoor comfort slightly, but a very high supply air flow rate will not bring those cases inside the comfort zone year round. 
In reality, however, it is difficult to seal an attic perfectly; and actual houses with unvented attics do have some leakage from the attic to the outdoors, sometimes at a significantly high rate. In those cases, it is even more critical to keep indoor moisture generation low to avoid moisture durability problems in the roof assembly.

Similar ongoing work will be completed, including modeling houses with appropriately designed unvented roof assemblies (for given climate zones) to determine how best to avoid moisture issues for all US climate zones. Those homes will be analyzed to determine the most important parameters for indoor comfort and roof assembly moisture durability.

\section{REFERENCES}

ANSI/ASHRAE (2013). ANSI/ASHRAE Standard 55-2013. 5.3.1. Atlanta, GA, American Society of Heating, Refrigerating and Air-conditioning Engineers, Inc.

ASHRAE (2002). ASHRAE Guideline 14-2002, Measurement of Energy Savings and Demand Savings. American Society of Heating, Refrigeration and Air-Conditioning Engineers, Inc., Atlanta, GA.

ASHRAE (2013). ASHRAE Handbook - Fundamentals - Heat, Air and Moisture Control in Building Assemblies. 25.17. Atlanta, GA, American Society of Heating, Refrigerating and Air-conditioning Engineers, Inc.

Boudreaux, P., et al. (2012). Occupancy Simulation in Three Residential Research Houses. ASHRAE Transactions;2012, Vol. 118 Issue 2, p625.

Boudreaux, P., et al. (2013). Moisture Performance of Sealed Attics in the Mixed-Humid Climate, Report ORNL/TM-2013/525, Building Technologies Research and Integration Center - Energy and Transportation Science Division, Oak Ridge National Laboratory, TN, USA.

Brown, S. A., et al. (2013). Review of Residential Low-Load HVAC Systems. Report PNNL-23017. Pacific Northwest National Laboratory, USA.

Christian, J., et al. (2010). Tennessee Valley Authority's Campbell Creek Energy Efficient Homes Project: 2010 First Year Performance Report July 1, 2009-August 31, 2010 - Report ORNL/TM-2010/206. Oak Ridge National Laboratory, TN.

Colon, C. (2011). New Construction Builders Challenge: Sealed Attic and High Efficiency HVAC in Central Florida: A Year in Review, Report FSEC-PF-454-11. Florida Solar Energy Commission, USA.

DOE (2013). Building America Top Innovations Hall of Fame Profile: Unvented, Conditioned Attics. . http://energy.gov/sites/prod/files/2014/01/f6/1 1c ba innov unventedconditionedattics 011713.pdf.

Gu, L. (2007). Airflow Network Modeling in EnergyPlus. Proceedings of the 10th International Building Performance Simulation Association Conference and Exhibition, 2007 Beijing, China.

Künzel, H. M., et al. (2011). Vapour control design in wooden structures including moisture sources due air exfiltration. 9th Nordic Symposium on Building Physics - NSB 2011, Tampere, Finland. 
Lstiburek, J. (2006). "Understanding Attic Ventilation." ASHRAE Journal 48(4): 36-38, 40, 42-45.

Ojanen, T. and K. Kumaran (1996). Effect of Exfiltration on the Hygrothermal Behaviour of a Residential Wall Assembly. Thermal Insul. and Bldg. Envs. Volume 19 - January.

Sherman, M. and D. Dickerhoff (1998). Air-Tightness of U.S. Dwellings. LBL-35700, Lawrence Berkeley Laboratory, Berkeley, California.

Woods, J., et al. (2013). Moisture Penetration Depth Model for Estimating Moisture Buffering in Buildings - Report NREL/TP-5500-57441. National Renewable Energy Laboratory, USA. 